\title{
New Thermodynamic Assessment of the Fe-Y System
}

\author{
I. Saenko ${ }^{1,2}$ - O. Fabrichnaya ${ }^{1}$ - A. Udovsky $y^{2,3}$
}

Submitted: 5 April 2017/in revised form: 30 May 2017/Published online: 13 July 2017

(c) ASM International 2017

\begin{abstract}
Critical review of the Fe-Y binary system has been performed and available experimental and calculated data have been collected. Thermodynamic parameters were optimized using the CALPHAD method. New experimental results of Gibbs energy and Ab-initio calculations of enthalpy of formation of intermetallic compounds have been taken into account. A self-consistent thermodynamic description of the Fe-Y system has been obtained. Problems of thermodynamic modelling in this system have been discussed. The results calculated using thermodynamic descriptions derived in the present work are compared with ones previously published using general " $\chi$ "”-criterion. This criterion allows taking into account the number independent optimized parameters used in the optimization. The calculated agreement criterion has shown that thermodynamic description of the present work describes experimental data better than earlier published ones.
\end{abstract}

Keywords CALPHAD $\cdot$ Fe-Y binary system $\cdot$ phase diagram $\cdot$ thermodynamic modeling

I. Saenko

ivan.saenko@iww.tu-freiberg.de

1 Institute of Materials Science, Technical University Bergakademie Freiberg, Gustav-Zeuner-Str. 5, 09599 Freiberg, Germany

2 A.A. Baikov Institute of Metallurgy and Materials Science, Russian Academy of Sciences, Leninskiy Prospect 49, Moscow, Russia 119991

3 National Research Nuclear University MEPhI, Kashirskoye sh., 31, Moscow, Russia 115409

\section{Introduction}

Rare-earth intermetallic compounds based on the Fe-Y system are of particular interest due to their potential industrial applications, such as permanent magnets, as well as hydrogen storage materials. ${ }^{[1,2]}$ Knowledge of phase relations and thermodynamic properties of the Fe-Y system is important for understanding of technological aspects of design and usage of materials and alloys based on the Fe-Y binary system. Moreover, thermodynamic assessment of the Fe-Y binary system can play an important role as subsystem for investigations and modelling of high-order systems, for example, for the modelling interaction strengthened ferrite steels by the oxide dispersion. ${ }^{[3]} \mathrm{Du}$ et al. $^{[4]}$ were the first who performed thermodynamic assessment of the Fe-Y system using CalPhaD method. There were several inconsistencies between experimental and calculated data on phase relations as well as thermodynamic properties. After that, thermodynamic modeling of Fe-Y system was carried out by Gong et al. in the frame of the thermodynamic investigation of the Fe-Ti-Y ternary system. ${ }^{[5]}$ The thermodynamic parameters for the Fe-Y system were optimized based on the phase diagram evaluation of Zhang et al. ${ }^{[6]}$ However, no parameters were published. Then calculated phase diagrams of Fe-Y system were independently presented by Lu et al. ${ }^{[7]}$ and Kardellass et al. ${ }^{[8]}$ without publishing of optimized thermodynamic parameters. Afterwards, full thermodynamic assessment and thermodynamic modeling of the iron-yttrium system were published by Kardellass et al. ${ }^{[9]}$ However, Ab-initio calculation of enthalpy ${ }^{[10]}$ and experimental results ${ }^{[11]}$ of Gibbs energy of formation for intermetallic compounds were not taken into account. The last thermodynamic assessment was performed by Konar et al. in the work. ${ }^{[12]}$ This work was an extended doctor thesis of $\mathrm{Konar}^{[13]}$ and 
taken into account all available experimental data except of Ab-initio calculation of Mihalkovic and Widom. ${ }^{[10]}$ It should be mentioned that in the works of Konar et al. ${ }^{[12,13]}$ the modified quasichemical model was applied for the liquid phase while intermetallic phases were described as stoichiometric compounds. However the modified quasichemical model is not compatible with the substitutional model. Therefore, the aim of this work is to assess the thermodynamic parameters for the Fe-Y system taking into account new experimental results ${ }^{[11]}$ and Ab-initio calculations ${ }^{[10]}$ resulting in a thermodynamic description, which could be applied for the further thermodynamic modeling of high-order systems.

\section{Experimental Data in the Fe-Y System}

Firstly, phase relationships in the Fe-Y system were investigated in the work of Domagala et al. ${ }^{[14]}$ and in the work of Farkas and Bauer. ${ }^{[15]}$ Domagala et al. ${ }^{[14]}$ have studied the entire composition range of the system using thermal-, $\mathrm{x}$-ray and microscopical analyses using very pure starting materials. Iron was stated to be $99.9 \%$ pure, and yttrium $99.0 \%$ pure. Major impurities of yttrium were $0.5 \%$ of $\mathrm{Zr}, 0.2 \%$ of $\mathrm{Ti}$ and $0.12 \%$ of $\mathrm{O}$. Specimens were produced using arcmelting and subsequently homogenized. Farkas and Bauer $^{[15]}$ investigated only Fe-rich region (about 70-100 wt.\% Fe). Results obtained by these two research groups are in conflict with each other in the Fe-rich region. Farkas and Bauer $^{[15]}$ used less pure component metals in comparison with the work, ${ }^{[14]}$ and specimens were not homogenized. Therefore, basic diagram proposed by Domagala et al. ${ }^{[14]}$ was accepted as more accurate one by Gscheidner ${ }^{[16]}$ and later by Kubuschewski ${ }^{[17]}$ in the first critical reviews of the Fe-Y system. However, Gscheidner assumed that accuracy of the experimental technique employed by Domagala et al. ${ }^{[14]}$ was not enough to provide very reliable results. Further, Kubuschewski ${ }^{[17]}$ corrected phase stoichiometry in order to bring the diagram into accordance with more recent results of crystallographic investigation. The version of the phase diagram presented by Kubuschewski ${ }^{[17]}$ with few corrections based on original data of Domagala et al. ${ }^{[14]}$ is shown in the Fig. 1. The last evaluation of the experimental data was performed by Zhang et al. ${ }^{[6]}$ This work was mostly focused on the recent crystal structure data, magnetic and thermodynamic properties, but not on the phase relations. Data on the solubility of the solid phases in the Fe-Y system, existence of metastable phase, crystal structures and lattice parameters of the intermetallic compounds, their magnetic properties, experimental results of mixing enthalpy of liquid phase and the Gibbs energy of formation of compounds were summarized and reviewed.
According to actual information state, there are four intermetallic compounds in the $\mathrm{Fe}-\mathrm{Y}$ system, namely $\mathrm{Fe}_{17} \mathrm{Y}_{2}, \mathrm{Fe}_{23} \mathrm{Y}_{6}, \mathrm{Fe}_{3} \mathrm{Y}$, and $\mathrm{Fe}_{2} \mathrm{Y}$. The reported compound " $\mathrm{Fe}_{5} \mathrm{Y}$ " with $\mathrm{CaCu}_{5}$ structure ${ }^{[16]}$ was not confirmed by the later experimental investigation of Taylor and Poldy. ${ }^{[19]}$ In the work of Tenhover, ${ }^{[20]}$ amorphous alloys were prepared by splat-cooling of Fe-Y liquid with 32 at.\% of yttrium and metastable phases were observed. It was shown that the crystallization of this glassy alloy occurs in two distinct steps associated with the formation of $h c p(Y)$ and the Laves phase compound $\mathrm{Fe}_{2} \mathrm{Y}$. A bcc phase was observed in the $\mathrm{Y}$ rich $\mathrm{Fe}-\mathrm{Y}$ alloys rapidly quenched by a melt spinning technique, as well as in the alloys close to eutectic composition of the Fe-Y equilibrium phase diagram (34.6 at.\% of $\mathrm{Fe}){ }^{[20]}$

Some of the stable phases, namely $\mathrm{Fe}_{17} \mathrm{Y}_{2}$ and $\mathrm{Fe}_{23} \mathrm{Y}_{6}$, earlier were considered to be " $\mathrm{Fe}_{9} \mathrm{Y}$ " and " $\mathrm{Fe}_{4} \mathrm{Y}$," respectively according to Domagala et al. ${ }^{[14]}$ In the further crystallographic study of Kripyakevich et al., ${ }^{[21]}$ it was shown that $\mathrm{Fe}_{9} \mathrm{Y}$ phase had an ideal stoichiometry of hexagonal $\mathrm{Ni}_{17} \mathrm{Th}_{2}$-type structure. Then, a structure investigation by Buschow ${ }^{[22]}$ revealed that $\mathrm{Fe}_{17} \mathrm{Y}_{2}$ had two modifications: the rhombohedral $\mathrm{Th}_{2} \mathrm{Zn}_{17}$ type and the hexagonal $\mathrm{Th}_{2} \mathrm{Ni}_{17}$ type. It was observed, that the samples annealed at $1273 \mathrm{~K}$ for 15 days contained both types of $\mathrm{Fe}_{17} \mathrm{Y}_{2}$, while the splat-cooled sample contained only the hexagonal type. ${ }^{[22]}$ Therefore, the hexagonal phase should be the high-temperature modification of the compound $\mathrm{Fe}_{17} \mathrm{Y}_{2}$. According to the investigation of Domagala et al., ${ }^{[14]}$ this compound melts congruently at $1673 \pm 25 \mathrm{~K}$. It should be mentioned, that the temperature of this transformation was not determined experimentally. Independent investigations of Kripyakevich et al. ${ }^{[21]}$ and Kharchenko et al. ${ }^{[23]}$ have defined that $\mathrm{Fe}_{4} \mathrm{Y}$ has an ideal stoichiometry of $\mathrm{Fe}_{23} \mathrm{Y}_{6}$ which is isomorphous to $\mathrm{Mn}_{23} \mathrm{Th}_{6}$. This intermetallic compound has fcc crystal structure with 116 atoms per unit cell. Their arrangement of atoms was described in detail by Smith et al. ${ }^{[24]}$ According to the work of Domagala et al., ${ }^{[14]} \mathrm{Fe}_{23} \mathrm{Y}_{6}$ melts congruently. Initially, possible existence of $\mathrm{Fe}_{3} \mathrm{Y}$ phase was reported by Domagala et al. ${ }^{[14]}$ They mentioned that the alloy of this composition always contained two or three phases and that no alloy could be prepared being free of segregation. Therefore, it was difficult to confirm the existence of this compound as a stable phase. Later it was established by van Vucht ${ }^{[25]}$ and Buschow ${ }^{[26]}$ that $\mathrm{Fe}_{3} \mathrm{Y}$ was a stable phase isomorphous to $\mathrm{PuNi}_{3}$. Domagala et al. ${ }^{[14]}$ reported that $\mathrm{Fe}_{3} \mathrm{Y}$ melts congruently at about $1673 \mathrm{~K}$. Kubuschewski ${ }^{[17]}$ considered this melting temperature as too high. $\mathrm{Fe}_{2} \mathrm{Y}$ is the Laves phase having cubic with $\mathrm{MgCu}_{2}$-type structure. This compound formed peritectically and showed a narrow homogeneity range. ${ }^{[14,27]}$ The crystal structure of $\mathrm{Fe}_{2} \mathrm{Y}$ was 
Fig. 1 Phase diagram of the Fe-Y system ${ }^{[14,17,18]}$

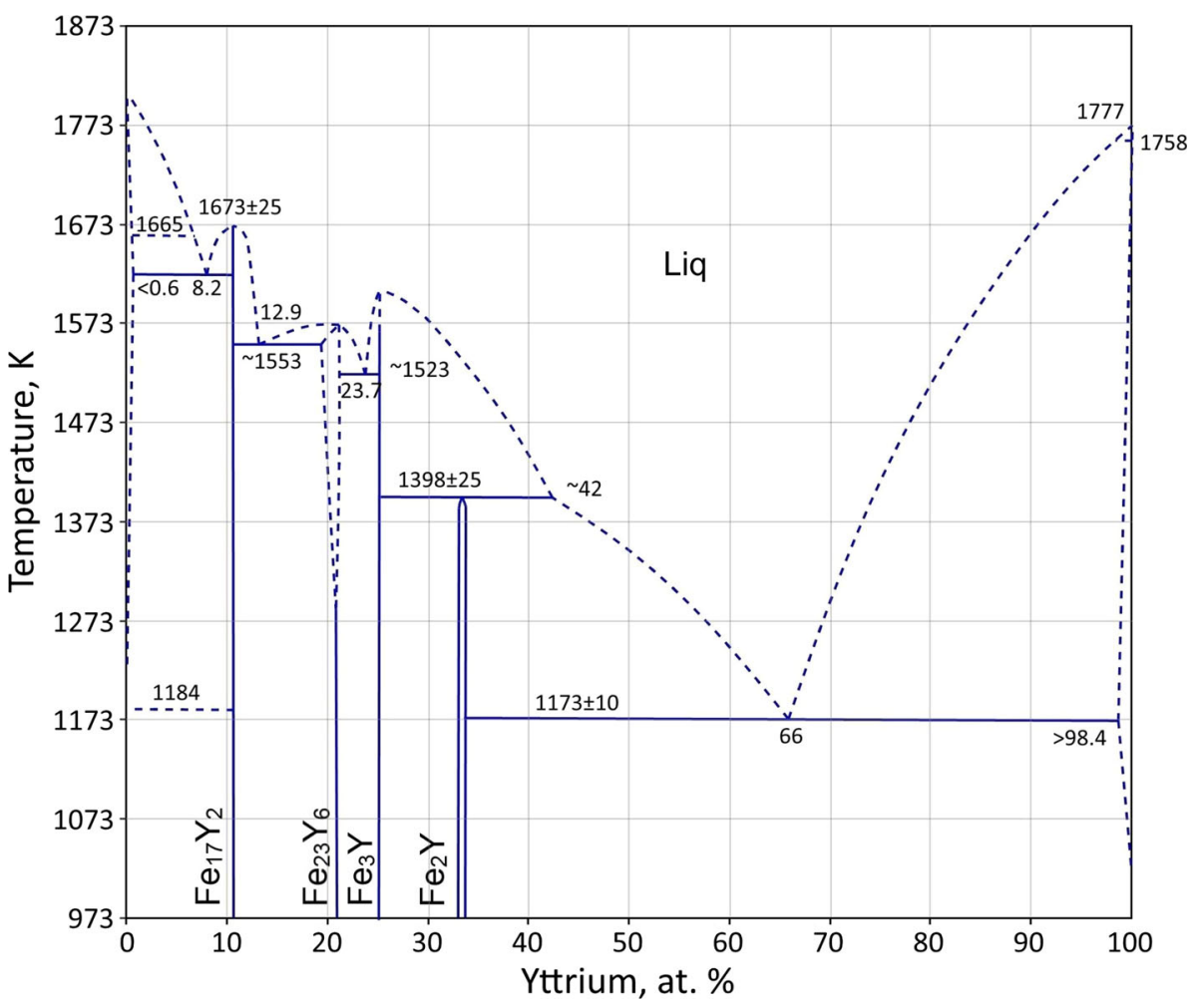

described in detail in the work of Dwight. ${ }^{[28]}$ The crystal structures of all solid phases are listed in the Table 1.

Hellawell ${ }^{[29]}$ reported that 1 at. $\%$ of yttrium lowers the $\gamma / \delta$ Fe transformation temperature by $3 \mathrm{~K}$. The effect of yttrium on the $\alpha / \gamma \mathrm{Fe}$ transformation is not known. ${ }^{[17]}$ However, solubility of yttrium in $\alpha \mathrm{Fe}$ was measured by $\mathrm{Li}$ and Xhing ${ }^{[31]}$ using EPMA (electron probe microanalysis) in the temperature interval of $873-1153 \mathrm{~K}$. The experimental results were presented by the relationship: $\ln \left(X_{\text {at.\%of } Y}\right)=$ $-2363.7 / T(\mathrm{~K})-(5.892 \pm 0.060)$. The terminal solid solubility of $\mathrm{Y}$ in $\gamma \mathrm{Fe}$ was not measured and Gscheidner ${ }^{[16]}$ assumed them to be less than 0.6 at.\%.

The first thermodynamic data was experimentally obtained in the work of Ryss et al. ${ }^{[32]}$ They measured the mixing enthalpy of liquid $\mathrm{Fe}-\mathrm{Y}$ alloys at temperature of $1600 \mathrm{~K}$. The data was obtained in the entire composition range with a step of 5 at.\%. The results showed a negative deviation from ideal behavior with a minimum of integral enthalpy of $-8.44 \mathrm{~kJ} \mathrm{~mol}^{-1}$ at 47 at.\% of Y. Later, partial enthalpy of mixing in the $\mathrm{Fe}$ rich liquid was measured by Sudavtsova et al. ${ }^{[33]}$ indicating less negative deviations from ideal behavior than obtained by Ryss et al. ${ }^{[32]}$

Nagai et al. ${ }^{[34]}$ measured yttrium and iron activities using the multi-Knudsen cell mass spectrometry in the temperature range of $1473-1573 \mathrm{~K}$ with pure elements as reference substances. The Fe-Y alloys were prepared using reagent grade yttrium (99.99\%) and electrolytic iron $(99.99 \%)$.
Table 1 Data on crystal structures of solid phases of the $\mathrm{Fe}-\mathrm{Y}$ system

\begin{tabular}{llllll}
\hline Phase & Crystal system & Space group & Pearson symbol & Prototype & Reference \\
\hline$\alpha \mathrm{Fe}$ & Cubic & $\operatorname{Im} \overline{3} m$ & $\mathrm{cI} 2$ & $\mathrm{~W}$ & 18 \\
$\gamma \mathrm{Fe}$ & Cubic & $F m \overline{3} m$ & $\mathrm{cF} 4$ & $\mathrm{Cu}$ & 18 \\
$\delta \mathrm{Fe}$ & Cubic & $\operatorname{Im} \overline{3} m$ & $\mathrm{cI} 2$ & $\mathrm{~W}$ & 18 \\
$\alpha \mathrm{Fe}_{17} \mathrm{Y}_{2}$ & Hexagonal & $P 6_{3} / m m c$ & $\mathrm{hP}$ & $\mathrm{Ni}_{17} \mathrm{Th}_{2}$ & 21,22 \\
$\beta \mathrm{Fe}_{17} \mathrm{Y}_{2}$ & Trigonal & $R \overline{3} m$ & $\mathrm{hR}$ & $\mathrm{Th}_{2} \mathrm{Zn}_{17}$ & 22 \\
$\mathrm{Fe}_{23} \mathrm{Y}_{6}$ & Cubic & $F m \overline{3} m$ & $\mathrm{cF} 116$ & $\mathrm{Mn}_{23} \mathrm{Th}_{6}$ & $21,23,24$ \\
$\mathrm{Fe}_{3} \mathrm{Y}$ & Trigonal & $R \overline{3} m$ & $\mathrm{hR}$ & $\mathrm{PuNi}_{3}$ & 25,26 \\
$\mathrm{Fe}_{2} \mathrm{Y}$ & Cubic & $F d \overline{3} m$ & $\mathrm{cF} 24$ & $\mathrm{Cu}_{2} \mathrm{Mg}_{2}$ & 29,30 \\
$\alpha \mathrm{Y}$ & Hexagonal & $P 6_{3} / m m c$ & $\mathrm{hP} 2$ & $\mathrm{Mg}$ & 16,18 \\
$\beta \mathrm{Y}$ & Cubic & $\operatorname{Im} \overline{3} m$ & $\mathrm{cI} 2$ & $\mathrm{~W}$ & 16,18 \\
\hline
\end{tabular}


Firstly, the Gibbs energies of phase formation for $\mathrm{Fe}_{17}$ $\mathrm{Y}_{2}, \mathrm{Fe}_{23} \mathrm{Y}_{6}, \mathrm{Fe}_{3} \mathrm{Y}$, and $\mathrm{Fe}_{2} \mathrm{Y}$ were determined by Subramanian and Smith $^{[35]}$ using EMF (electro motive force) method in the temperature range of 893-1271 K. Enthalpies and entropies of formation of phases were obtained by second law evaluation of EMF data. The further experimental evaluation of the enthalpy and entropy of formation of $\mathrm{Fe}_{17} \mathrm{Y}_{2}$ was performed by Gozzi et al. ${ }^{[11]}$ based on EMF measurements. Comparison of the obtained results with the previous results showed good agreement of Gibbs energies of formation, as well as, enthalpies and entropies. However, the measurement was carried out also only in the narrow temperature range from 825 up to $980 \mathrm{~K}$ and enthalpies and entropies of formation of phases were evaluated by the second law as well. Watson and Bennett ${ }^{[36]}$ used a simple Friedel-type d-band model in order to predict enthalpies of formation of Fe-Y phases. The predicted value for the ficticious compound FeY was of the order of $-42 \mathrm{~kJ} \mathrm{~mol}^{-1}$ (values are given per mole of atoms) ${ }^{[36]}$ and later was re-evaluated to be equal to $-13 \mathrm{~kJ} \mathrm{~mol}^{-1}$. $^{[37]}$ In contrast, the Miedema theory ${ }^{[38]}$ predicted the enthalpies of formation of $\mathrm{Fe}-\mathrm{Y}$ phases to be of the order lower and was calculated as $-2 \mathrm{~kJ} \mathrm{~mol}^{-1}$. [39] However, these calculations differ from experimental values of Subramanian and Smith. ${ }^{[35]}$ Additionally, Mihalkovic and Widom ${ }^{[10]}$ performed $\mathrm{Ab}$ initio calculation of enthalpies of formation of intermetallic phases at $0 \mathrm{~K}$. Obtained results were in good agreement with experimental data of Subramanian and Smith. ${ }^{[35]}$ Based on the first principle calculations of Mihalkovic and Widom, ${ }^{[10]}$ the $\mathrm{Fe}_{17} \mathrm{Y}_{2}$ and $\mathrm{Fe}_{23} \mathrm{Y}_{6}$ phases were considered to be unstable at low temperatures. However, there is no experimental data confirming this.

First magnetic studies were carried out by Kirchmayr, ${ }^{[40]}$ Kirchmayr and Steiner ${ }^{[41]}$ and Besnus et al. ${ }^{[42]}$ As it was mentioned above, alloys in the Fe-Y system are of interest as potential permanent magnetic materials. Therefore, many investigations of magnetic properties of intermetallic compounds of the Fe-Y system were subsequently performed. Experimental data on Curie temperature and magnetic moment are listed in the Table 2.

It should be mentioned that magnetocaloric effect in the $\mathrm{Fe}_{17} \mathrm{Y}_{2}$ compound has been studied in the work of Mandal et al. ${ }^{[58]}$ Herewith, the ferromagnetic-to-paramagnetic phase transition was studied by measuring the heat capacity at constant pressure $\left(\mathrm{C}_{\mathrm{P}}\right)$ using a PPMS device (quantum design) in the temperature range of 2-300 K. ${ }^{[58]}$ However, $\mathrm{X}$-ray diffraction pattern for the sample has shown deviation from literature data on crystal structure, ${ }^{[21,22]}$ namely some reflections were absent in the diffraction pattern of the obtained samples. Moreover, according to Mandal et al., ${ }^{[58]}$ the magnetic transformation occurs at $295 \mathrm{~K}$. This temperature significantly differs from the mean value of
Curie temperature for the $\mathrm{Fe}_{17} \mathrm{Y}_{2}$ compound. A reason of this difference could be a deviation of the sample composition from nominal. The magnetocaloric effect at $295 \mathrm{~K}$ had a contribution in the heat capacity of samples. This can result in overestimated value for standard entropy at 298.15 K. Therefore, experimental technique of the sample preparation used by Mandal et al. ${ }^{[58]}$ was not sufficient in order to obtain heat capacity data of high accuracy, which allow precise determination of the standard entropy for magnetic intermetallic compound $\mathrm{Fe}_{17} \mathrm{Y}_{2}$ at $298.15 \mathrm{~K}$.

As it was said above, thermodynamic assessment of the Fe-Y system performed by Du et al. ${ }^{[4]}$ suffered by several inconsistencies between experimental and calculated data for phase relations as well as for thermodynamic properties. In their work, the compound $\mathrm{Fe}_{23} \mathrm{Y}_{6}$ was formed by the peritectic reaction $\mathrm{Liq}+\mathrm{Fe}_{3} \mathrm{Y} \rightarrow \mathrm{Fe}_{23} \mathrm{Y}_{6}$ (at $1573 \mathrm{~K}$ ) instead of its congruent melting and the eutectic reaction $\mathrm{Liq} \rightarrow \mathrm{Fe}_{3} \mathrm{Y}+\mathrm{Fe}_{23} \mathrm{Y}_{6}$ (at $1523 \mathrm{~K}$ ). The $\mathrm{Fe}_{2} \mathrm{Y}$ and $\mathrm{Fe}_{23} \mathrm{Y}_{6}$ compounds have been modeled as stoichiometric phases. This assessment was performed 20 years ago ${ }^{[4]}$ and recent data are not accounted there. Thermodynamic assessments of Fe-Y system performed by Gong et al. ${ }^{[5]}$ and then $\mathrm{Lu}$ et al. ${ }^{[7]}$ and Kardellass et al. ${ }^{[8]}$ presented only phase diagram without publishing thermodynamic parameters. Moreover, these optimizations have been carried out based on limited amount of experimental data and no comparison of calculated thermodynamic properties with available experimental results was presented. Therefore, results obtained in the works ${ }^{[4,5,7,8]}$ will not be further discussed in the present paper.

In the thermodynamic assessment of the Fe-Y system performed by Kardellass et al., ${ }^{[9]}$ the excess Gibbs energy of the liquid phase has been described using a polynomial temperature dependence (PTD) in the form of $A+B T+$ $C T^{2}$ and an exponential temperature dependence (ETD) of mixing parameters by Kaptay in the form of $A \cdot \exp \left(-\frac{T}{B}\right) \cdot{ }^{[66]}$ The $C T^{2}$ term in the PTD has been added in order to avoid the occurrence of an unwanted inverted miscibility gap in the liquid phase at high temperatures. ${ }^{[9]}$ The addition of this term into the equation of the mixing parameter can be interpreted as some contribution of the excess heat capacity into the excess Gibbs energy. However, the information about excess heat capacity is not available. Optimization of excess Gibbs energy using Kaptay's ETD was used by Kardellass et al. ${ }^{[9]}$ as the way to avoid the high temperature artefacts of inverted miscibility gap, caused by linear temperature dependence. In the work of Kardellass et al., ${ }^{[9]}$ it was stated, that the thermodynamic description optimized by Kaptay's ETD reproduces experimental data better than the description optimized by PTD. However, it was revealed that both thermodynamic descriptions presented by Kardellass et al. ${ }^{[9]}$ gave 
Table 2 Experimental data on Curie temperatures and mean magnetic moments of intermetallic compounds of the Fe-Y system

\begin{tabular}{|c|c|c|c|}
\hline Phase & $\begin{array}{c}\text { Curie } \\
\text { temperature, } \mathrm{K}\end{array}$ & $\begin{array}{c}\text { Mean magnetic moment } \mu_{\mathrm{B}} \\
\text { per Fe atom }\end{array}$ & References \\
\hline \multirow[t]{16}{*}{$\mathrm{Fe}_{17} \mathrm{Y}_{2}$} & 322 & $\ldots$ & 43 \\
\hline & 300 & 2.00 & 44 \\
\hline & 341 & 2.01 & 45 \\
\hline & 310 & 1.92 & 46 \\
\hline & 328 & 2.20 & 47 \\
\hline & 336 & 2.00 & 48 \\
\hline & 309 & 1.99 & 49 \\
\hline & 308 & $\ldots$ & 50 \\
\hline & 324 & 2.00 & 51 \\
\hline & 309 & 2.00 & 52 \\
\hline & 327 & 1.78 & 53 \\
\hline & $\ldots$ & 2.01 & 54,55 \\
\hline & $\ldots$ & 2.04 & 55,56 \\
\hline & 324 & 1.93 & 26 \\
\hline & 300 & 1.79 & 57 \\
\hline & 295 & $\ldots$ & 58 \\
\hline \multirow[t]{6}{*}{$\mathrm{Fe}_{23} \mathrm{Y}_{6}$} & 484 & 1.86 & 59 \\
\hline & 490 & 1.88 & 40 \\
\hline & $\ldots$ & 1.91 & 55,56 \\
\hline & $\ldots$ & 1.97 & 55,60 \\
\hline & $\ldots$ & 1.93 & 41,55 \\
\hline & 481 & 1.87 & 26 \\
\hline \multirow[t]{3}{*}{$\mathrm{Fe}_{3} \mathrm{Y}$} & $\ldots$ & 1.67 & 55,56 \\
\hline & $\ldots$ & 1.63 & 55,61 \\
\hline & 569 & 1.75 & 26 \\
\hline \multirow[t]{7}{*}{$\mathrm{Fe}_{2} \mathrm{Y}$} & 552 & $\ldots$ & 62 \\
\hline & 545 & $\ldots$ & 63 \\
\hline & 545 & 1.45 & 30 \\
\hline & 534 & 1.44 & 64 \\
\hline & 545 & 1.40 & 40 \\
\hline & 545 & 1.45 & 65 \\
\hline & 542 & 1.45 & 26 \\
\hline
\end{tabular}

miscibility gap in the liquid phase at low temperatures that could cause artefacts in high-order systems. Moreover, it should be mentioned, that results calculated by Kardellass et al. ${ }^{[9]}$ have significant deviations from experimental data on Gibbs energy, enthalpy and entropy of formation ${ }^{[35]}$ because available data on Gibbs energy ${ }^{[11]}$ and enthalpy ${ }^{[10]}$ of formation were not taken into account in optimization. ${ }^{[9]}$ It should be noted that the activity data obtained by vapor pressure measurements ${ }^{[34]}$ indicated larger negative deviations from ideal behavior than calculated using both descriptions of Kardellass et al. ${ }^{[9]}$

In thermodynamic assessments presented by Konar et al. in the works, ${ }^{[12,13]}$ the modified quasichemical model was used to describe the liquid solution. It should be also noted that homogeneity ranges in the $\mathrm{Fe}_{23} \mathrm{Y}_{6}$ and $\mathrm{Fe}_{2} \mathrm{Y}$ indicated by Ref 14 and 17 were not taken into account by Konar et al. ${ }^{[12,13]}$ The latest thermodynamic description ${ }^{[12]}$ does not reproduce phase diagram better than already mentioned description. ${ }^{[9]}$ The same problem to reproduce vapor pressure data ${ }^{[34]}$ was found in both assessments Ref 12 and 9 . It should be mentioned that the enthalpy and entropies of formation of intermetallic compounds were not well reproduced by Konar et al. ${ }^{[12]}$ Because the model used by Konar et al. ${ }^{[12]}$ is not compatible with the one used in the present work and taking into account the fact that that the description of the work ${ }^{[12]}$ does not provide substantially better fit to experimental data than other available descriptions the results of assessment ${ }^{[12]}$ will not be further discussed.

\section{Thermodynamic Modeling}

The thermodynamic descriptions of Gibbs energy of the pure element $i(i=\mathrm{Fe}, \mathrm{Y})$ in the $\Phi$ phase referred to the enthalpy of its phase at $298.15 \mathrm{~K}$ were taken from SGTE database version $5.0^{[67]}$ in the following form:

$$
\begin{aligned}
G H \Phi_{i}= & { }^{0} G_{i}^{\Phi}(T)-{ }^{0} H_{i}^{\Phi}(298.15 \mathrm{~K}) \\
= & a+b T+c T \ln T+d T^{2}+e T^{3}+f T^{-1}+g T^{7} \\
& +h T^{-9}
\end{aligned}
$$

Magnetic contribution to the thermodynamic properties was taken into account according to Inden-Hillert-Jarl ${ }^{[68]}$ formalism (Eq 2).

$G_{m}^{\Phi, \mathrm{mag}}=R T \ln \left(\beta_{0}+1\right) g(\tau)$

where $\tau=T / T^{*}, T^{*}$ is the critical temperature (the Curie temperature $T_{\mathrm{C}}$ for ferromagnetic materials or the Neel temperature $\mathrm{T}_{\mathrm{N}}$ for antiferromagnetic materials), $\beta_{0}$ the average magnetic moment per atom and $g(\tau)$ is a function depending on $\tau .^{[69]}$

Substitutional solutions were modeled using following equation:

$$
\begin{aligned}
G_{m}^{\Phi} & =G_{m}^{\Phi, \text { srf }}+G_{m}^{\Phi, \text { conf }}+G_{m}^{\Phi, \text { Ex }} \\
& =\sum_{i}^{n} x_{i}^{0} G_{i}^{\emptyset}+R T \sum_{i}^{n} x_{i} \ln x_{i}+G_{m}^{\Phi, \text { Ex }}
\end{aligned}
$$

where $G_{m}^{\Phi, \text { srf }}=\sum_{i}^{n} x_{i}^{0} G_{i}^{\Phi}$ is the surface of reference term, $G_{m}^{\Phi, \text { conf }}=R T \sum_{i}^{n} x_{i} \ln x_{i}$ is Gibbs free energy resulting from the configurational entropy of mixing for disorder solution, and $G_{m}^{\Phi, \text { Ex }}$ is the excess Gibbs free energy of mixing.

The excess Gibbs free energy of mixing was modeled using Redlich-Kister polynomials, ${ }^{[70]}$ expressed as:

$G_{m}^{\Phi, \text { Ex }}=x_{A} x_{B} \sum_{v=0}^{n}{ }^{v} L_{A, B}^{\Phi}\left(x_{A}-x_{B}\right)^{v}$ 
The Gibbs energy $G_{A_{a} B_{b}}(T)$ of a stoichiometric phase $A_{a} B_{b}$ in case of absence of heat capacity data was modeled as:

$$
\begin{aligned}
& G_{A_{a} B_{b}}-a \cdot{ }^{0} H_{A}^{\Phi}(298.15 \mathrm{~K})-b \cdot{ }^{0} H_{B}^{\Phi}(298.15 \mathrm{~K}) \\
& \quad=a \cdot \operatorname{GHSER}_{A}+b \cdot \operatorname{GHSER}_{B}+\alpha+\beta \cdot T
\end{aligned}
$$

where $\mathrm{GHSER}_{i}$ is the Gibbs energy of the pure element $i$ referred to the enthalpy of pure element $i$ at $298.15 \mathrm{~K}$ in its standard element reference (SER) state, $\alpha$ and $\beta$ are parameters to be optimized.

Homogeneity ranges of BCC, FCC and HCP phase, as well as the liquid phase were described using substitutional model with one sublattice in the form of $(\mathrm{Fe}, \mathrm{Y})$. Stable intermediate compounds in the Fe-Y system which have homogeneity ranges were described by the two-sublattice model with convenient substitution in each sublattice in form of compound energy formalism. ${ }^{[71]}$ For the considered case $(\mathrm{Fe}, \mathrm{Y})_{\mathrm{a}}(\mathrm{Fe}, \mathrm{Y})_{\mathrm{b}}$, mole fraction of all endmembers in the first $\left(y_{\mathrm{Fe} / \mathrm{Y}}^{\prime}\right)$ and second $\left(y_{\mathrm{Y} / \mathrm{Fe}}^{\prime \prime}\right)$ sublattice must be considered in the Eq 3 as following.

$$
\begin{aligned}
& G_{m}^{\Phi, \mathrm{srf}}+G_{m}^{\Phi, \mathrm{conf}}+G_{m}^{\Phi, \mathrm{Ex}}=y_{\mathrm{Fe}}^{\prime} y_{\mathrm{Y}}^{\prime \prime} \cdot{ }^{0} G_{\mathrm{Fe}: \mathrm{Y}}^{\Phi}+y_{\mathrm{Fe}}^{\prime} y_{\mathrm{Fe}}^{\prime \prime} \cdot{ }^{0} G_{\mathrm{Fe}: \mathrm{Fe}}^{\Phi} \\
& +y_{\mathrm{Y}}^{\prime} y_{\mathrm{Y}}^{\prime \prime} \cdot{ }^{0} G_{\mathrm{Y}: \mathrm{Y}}^{\phi}+y_{\mathrm{Y}}^{\prime} y_{\mathrm{Fe}}^{\prime \prime} \cdot{ }^{0} G_{\mathrm{Y}: \mathrm{Fe}}^{\Phi} \\
& +R T\left[a\left(y_{\mathrm{Fe}}^{\prime} \ln \left(y_{\mathrm{Fe}}^{\prime}\right)+y_{\mathrm{Y}}^{\prime} \ln \left(y_{\mathrm{Y}}^{\prime}\right)\right)\right. \\
& \left.+b\left(y_{\mathrm{Y}}^{\prime \prime} \ln \left(y_{\mathrm{Y}}^{\prime \prime}\right)+y_{\mathrm{Fe}}^{\prime \prime} \ln \left(y_{\mathrm{Fe}}^{\prime \prime}\right)\right)\right] \\
& +G_{m}^{\Phi, \mathrm{Ex} 0} G_{\mathrm{Fe}: \mathrm{Y}}^{\Phi}=a \cdot \mathrm{GHSER}_{\mathrm{Fe}}+b \cdot \mathrm{GHSER}_{Y} \\
& +\alpha+\beta \cdot T^{0} G_{\mathrm{Fe}: \mathrm{Fe}}^{\Phi}=(a+b) \cdot \mathrm{GHSER}_{\mathrm{Fe}} \\
& +\gamma^{0} G_{\mathrm{Y}: \mathrm{Y}}^{\Phi}=(a+b) \cdot \mathrm{GHSER}_{\mathrm{Y}}+\sigma^{0} G_{\mathrm{Y}: \mathrm{Fe}}^{\Phi} \\
& =a \cdot \operatorname{GHSER}_{Y}+b \cdot \mathrm{GHSER}_{\mathrm{Fe}}-\alpha-\beta \cdot T \\
& +\gamma+\sigma
\end{aligned}
$$

In the frame of the present work, the excess energy contribution $G_{m}^{\Phi, \text { Ex }}$ was zero, as mixing parameters ${ }^{0} L_{\mathrm{Fe}, \mathrm{Y}: \mathrm{Y}}^{\Phi}=$ ${ }^{0} L_{\mathrm{Fe}, \mathrm{Y}: \mathrm{Fe}}^{\Phi}$ and ${ }^{0} L_{\mathrm{Fe}: \mathrm{Y}, \mathrm{Fe}}^{\Phi}={ }^{0} L_{\mathrm{Y}: \mathrm{Y}, \mathrm{Fe}}^{\Phi}$ were stated to be zero.

The assessment of thermodynamic parameters and phase diagram calculations of the $\mathrm{Fe}-\mathrm{Y}$ system were performed using Thermo-Calc program set using correspondently PARROT module and POLY-3 module. ${ }^{[72,73]}$

\section{Optimization Strategy}

At the first step of the optimization procedure, intermetallic compounds $\mathrm{Fe}_{2} \mathrm{Y}$ and $\mathrm{Fe}_{23} \mathrm{Y}_{6}$ with homogeneity ranges were accepted to be stoichiometric. Then, they were treated using a two-sublattice model with convenient substitution in each sublattice: $(\mathrm{Fe}, \mathrm{Y})_{2}(\mathrm{Y}, \mathrm{Fe})$ and $(\mathrm{Fe}, \mathrm{Y})_{23}(\mathrm{Y}, \mathrm{Fe})_{6}$ respectively.

The substitutional model was accepted to describe the liquid phase. The binary interaction parameters of ${ }^{0} L_{A, B}^{\emptyset}$ were assessed in the present work using the linear temperature dependence $A-B \cdot T$. According to this equation, the enthalpy of mixing and the excess entropy of mixing related to the constant parameters $A$ and $B$, respectively. According to Kaptay, this is a very rough assumption. ${ }^{[66]}$ Generally, if $B$ has negative sign then the excess Gibbs energy at mid-composition grows positively with the temperature. This results in an inverted miscibility gap with a lower critical temperature of $T_{\mathrm{c}, \text { min }}=A /(B+2 R)^{[66]}$ (where $R$ is the gas constant). However, according to Schmid-Fetzer et al., ${ }^{[74]}$ it does not contradict with the fact that real systems exist at temperatures lower than critical temperature and de-mixing occurs over some very high temperature range. Therefore, the linear temperature dependence can be used in the defined temperature interval up to $T_{\mathrm{c}, \mathrm{min}}$.

Kaptay ${ }^{[66]}$ suggested a possibility of trying to avoid the artificial miscibility gap completely, by bringing liquid excess parameters to zero at high temperatures using an exponential function of the following form:

${ }^{v} L_{A, B}^{\mathrm{Liq}}=h_{0} \exp \left(-\frac{T}{\tau_{0}}\right)$

where $h_{0}$ and $\tau_{0}$ are the two adjustable parameters

Schmid-Fetzer et al. ${ }^{[7]}$ have mentioned, that Kaptay's model allows avoiding the inverted gap, while other artifacts at low temperature can be observed. In the case of the negative enthalpy of mixing in liquid alloys, one parameter must have $h_{0}<0$, resulting in negative excess Gibbs energy. The exponential function, however, exaggerates this negative excess Gibbs energy at very low temperature, resulting in the re-stabilization of the liquid phase way below the solidus. Later, Kaptay revised the exponential excess Gibbs energy model in to the form of the combined linear-exponential model. ${ }^{[75]} \mathrm{He}$ stated that the combined linear-exponential model should be used instead of the exponential model in the case of occurring of artifacts at low temperatures. However, the application of such complex models to describe the excess Gibbs energy can be unreasonable. Therefore, linear temperature dependence was applied in the present work to assess binary interaction parameters of ${ }^{v} L_{A, B}^{\emptyset}$ with special care to avoid a miscibility gap at high temperatures.

In order to decrease deviation between calculated and experimental data, method of least squares has been used with help of the PARROT module of Thermo-Calc. Individual weights have been predetermined for every type of experimental data considering possible deviation and accuracy of the each experimental method. As it was said above, a contribution of heat capacity into the enthalpy of formation have not been considered (i.e. $\Delta C_{p}=$ 
0 in the range between 0 and $298.15 \mathrm{~K}$ ). Therefore, results of ab-initio calculations of enthalpies of formation of intermetallic compounds were taken into account as enthalpies of formation at $298.15 \mathrm{~K}$. It should be mentioned that the results of Sudavtsova et al. ${ }^{[33]}$ were not used in optimization because they are obtained in the narrow range of compositions deviation from accepted data of Ryss et al. ${ }^{[32]}$

Increasing of number of excess interaction parameters and complication of their temperature dependence description do not always lead to the best accordance between experimental data and calculated results. Therefore, optimization strategy was aimed to get the best agreement of the thermodynamic description with collected literature data on phase relations and thermodynamic properties using a minimum of parameters. The general " $\chi^{2}$ "-criterion (Eq 8) ${ }^{[76]}$ has been used during the optimization process as a method to compare current in the present work and published earlier thermodynamic descriptions considering its number of independent optimized parameters.

$\chi^{2}=\sum_{i=1}^{N}\left[\frac{\alpha_{i . \text { cal. }}-\alpha_{i . \text { exp. }}}{\delta \alpha_{i . \exp .}}\right]^{2} \cdot(N-p-1)^{-1}$

where $\alpha_{i . \text { exp. }}$ an experimental value with an error $\delta \alpha_{i . \text { exp. }}$; $\alpha_{i . \text { cal. }}$ a calculated value of a thermodynamic description; $p$ a number of independent optimized parameters; $N$ a general number of experimental values.

The $\mathrm{Fe}_{17} \mathrm{Y}_{2}$ phase was described without the high temperature modification because of an insufficiency of experimental information. Experimental results of invariant reactions and phase relations had the most weight during the optimization of thermodynamic parameters of the Fe-Y system. Average values of experimental Curie temperature and mean magnetic moment of intermetallic compounds were used in order to consider the magnetic contribution to the thermodynamic properties. The Curie temperature and mean magnetic moment for FCC and BCC phases were taken according to SGTE database version 5.0. ${ }^{[67]}$

\section{Results and Discussion}

Optimized thermodynamic parameters of the obtained thermodynamic description are listed in the Table 3. The calculated Fe-Y phase diagram is presented in the Fig. 2 along with experimental data. Comparison of calculated invariant reactions with experimental data and results obtained in the previous thermodynamic assessment ${ }^{[9]}$ are presented in the Table 4. It should be mentioned, that methods used by Domagala et al. ${ }^{[14]}$ to determine solidus lines of the diagram were based on the optical determination of visible melting. Therefore, that experimental data obtained in the work of Domagala et al. ${ }^{[14]}$ had significant uncertainty. The most accurate temperature was stated for eutectic reaction $\mathrm{Liq} \leftrightarrow \mathrm{Fe}_{2} \mathrm{Y}+\alpha \mathrm{Y}$ with an error of $\pm 10 \mathrm{~K}$. Temperature deviations of eutectic $\mathrm{Liq} \leftrightarrow \gamma \quad \mathrm{Fe}+\mathrm{Fe}_{17} \mathrm{Y}_{2}$, congruent $\mathrm{Liq} \leftrightarrow \mathrm{Fe}_{17} \mathrm{Y}_{2}$ and peritectic Liq $+\mathrm{Fe}_{3} \mathrm{Y} \leftrightarrow \mathrm{Fe}_{2} \mathrm{Y}$ reactions were given as $\pm 25 \mathrm{~K}$. Other temperatures were denoted as rough values. The error of these values can be estimated to be about $\pm 50 \mathrm{~K}$. An accuracy of the published values on chemical compositions of the liquid phase was given to be about 0.1 at.\% for all invariant reactions. However, considering investigation methods used by Domagala et al., ${ }^{[14]}$ it can be stated, that obtained experimental results of chemical compositions of invariant reactions cannot be defined more accurately than \pm 1 at.\%. It must be mentioned, that the chemical composition of liquid in the peritectic reaction $\mathrm{Liq}+\mathrm{Fe}_{3} \mathrm{Y} \leftrightarrow \mathrm{Fe}_{2} \mathrm{Y}$ has been denoted as a rough value. Therefore, it can be concluded, that good agreement of calculated results with experimental data on phase relations within error ranges was achieved.

Figure 3 shows the integral enthalpy of mixing of the liquid phase versus the mole fraction of yttrium at temperature of $1873 \mathrm{~K}$ calculated in the present work and in the work of Kardellass et al. ${ }^{[9]}$ in comparison with experimental data of Ryss et al. ${ }^{[32]}$ The reference state of both elements was accepted as liquid at $1873 \mathrm{~K}$. The calculated curve had a minimum value of $-7.96 \mathrm{~kJ} \mathrm{~mol}^{-1} 47$ at. $\% \mathrm{Y}$, which perfectly agrees with experimental value of $-8.44 \mathrm{~kJ} \mathrm{~mol}^{-1}$ obtained for the same composition. ${ }^{[32]} \mathrm{It}$ is clearly evident that the calculated results obtained in the present work have reproduced the experimental data better than in the work of Kardellass et al. ${ }^{[9]}$ The maximal deviation is $\sim 5 \%$.

Figure 4 presents the activities of iron and yttrium calculated data of this work compared to the measured ones using Knudsen effusion mass spectrometry (KEMS) by Nagai et al. ${ }^{[34]}$ The activities were found to be inconsistent with calculations of the present work, especially activity of iron. According to the experimental results, activities of iron and yttrium should have large negative deviation from ideal behavior. In the present optimization less negative deviation from ideal behavior in liquid phase than obtained by ${ }^{[34]}$ is required in order to reproduce the phase diagram (see Fig. 1), as well as experimental data on the Gibbs energy, enthalpy and entropy of formation of intermetallic compounds obtained in the works. ${ }^{[10,11,35]}$ Using obtained values $a_{F e}$ and $a_{Y}$, Nagai et al. ${ }^{[34]}$ determined the temperature dependence of the Gibbs energy of formation of $\mathrm{Fe}_{3} \mathrm{Y}$ to be $\left(-29.75+8.5 \cdot 10^{-3} \cdot T(K)\right) \mathrm{kJ} \mathrm{mol}^{-1}$. Obtained result considerably differs from values obtained in other works. ${ }^{[10,11,35]}$ Consequently, it can be concluded, that 


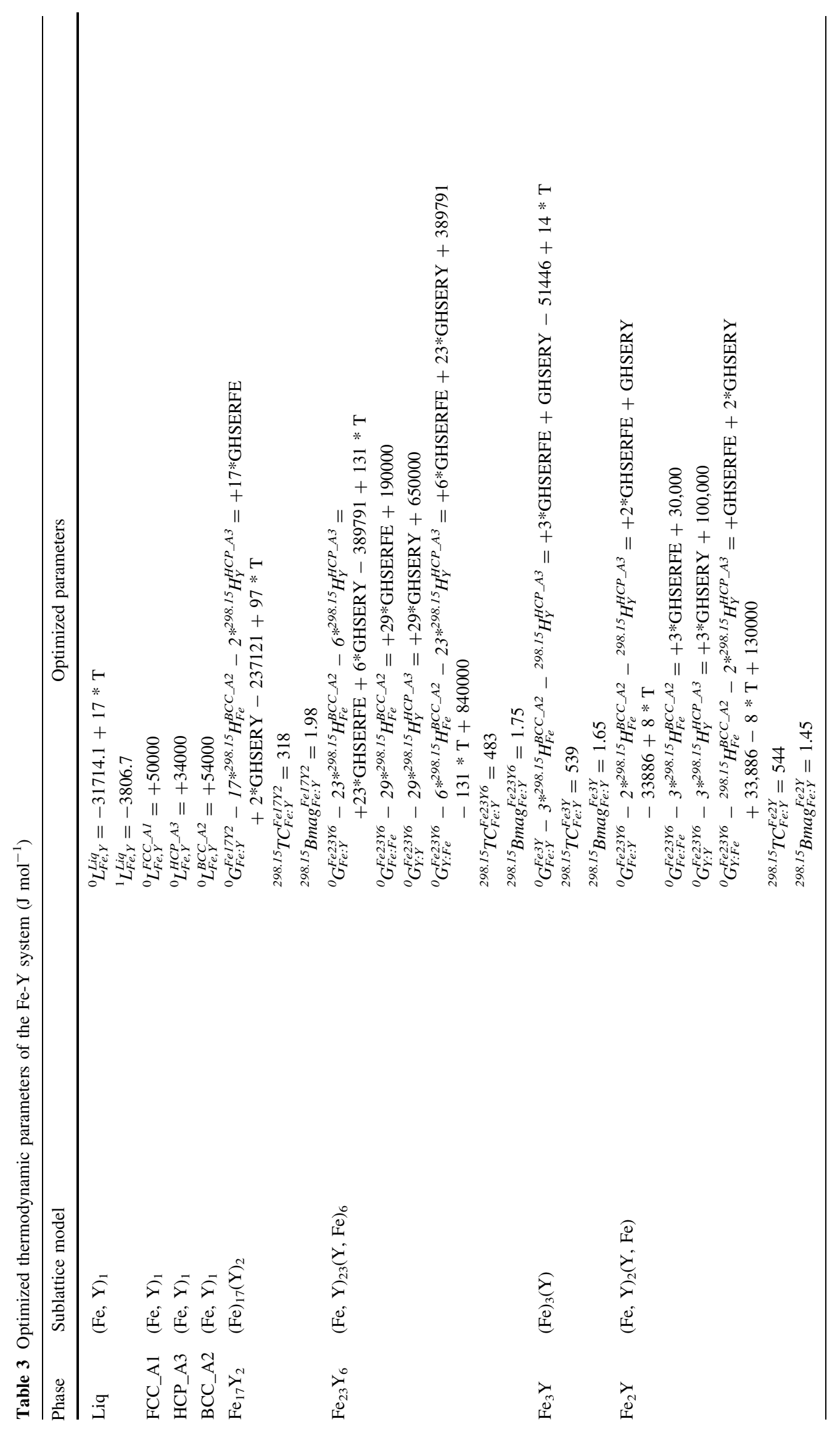




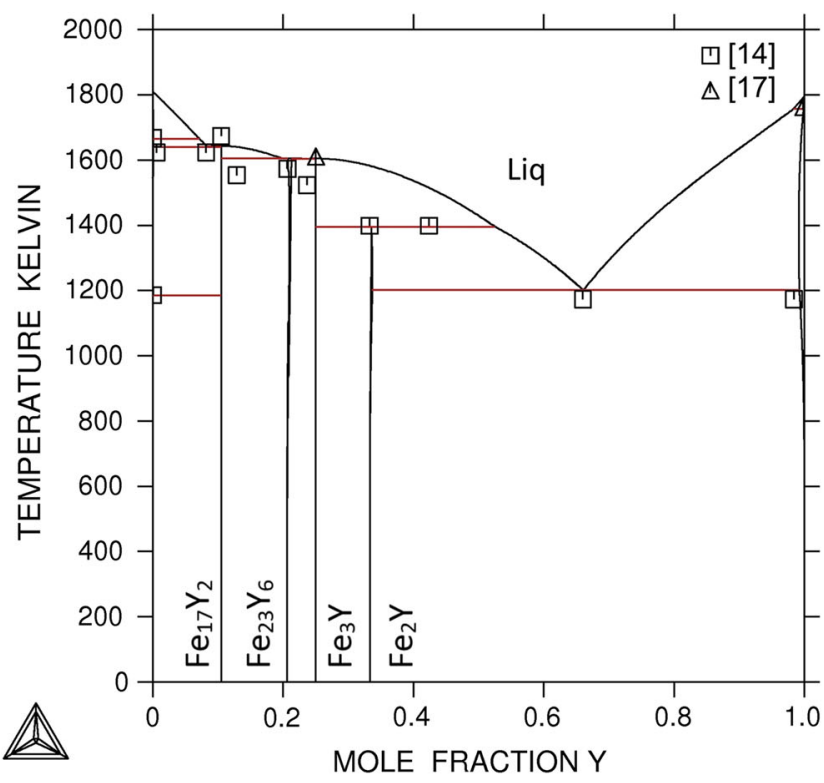

Fig. 2 Calculated Fe-Y phase diagram with experimental data ${ }^{[14,17]}$

obtained experimental information and activity data by Nagai et al. ${ }^{[34]}$ are inconsistent. Similar inconsistencies were observed for the database of Kardellass et al. ${ }^{[9]}$ It should be mentioned the substantial inconsistencies were also observed for the calculations in the system of $\mathrm{Fe}-\mathrm{La}^{[77]}$ in comparison with experimental data of Nagai et al. ${ }^{[34]}$ According to Konar et al., ${ }^{[77]}$ a reason of the inconsistencies could be a significant error in ion current measurements in the KEMS.

The Gibbs energy, enthalpy and entropy of formation calculated in the present work are compared with experimental data and calculations of Kardellass et al. ${ }^{[9]}$ are listed in the Table 5. It can be seen that there is reasonable agreement between calculated and experimental results for the Gibbs energy, enthalpy and entropy of formation. It should be mentioned, that the $\mathrm{Fe}_{17} \mathrm{Y}_{2}$ and $\mathrm{Fe}_{23} \mathrm{Y}_{6}$ compounds were stated to be unstable at $0 \mathrm{~K}$ based on the results of Ab-initio calculations of Mihalkovic and Widom. Nevertheless, there are no experimental data about any phase transformation in the Fe-Y binary system at low temperatures. Additionally, it should be noted, that these results of first principle calculations had minor statistical weight during the optimization process in comparison with experimental data. However, as it can be seen in the Table 5, there is acceptable accordance between Ab-inition results and values calculated in this work. The Gibbs energy and enthalpy of formation calculated using the thermodynamic description of the present work are compared with

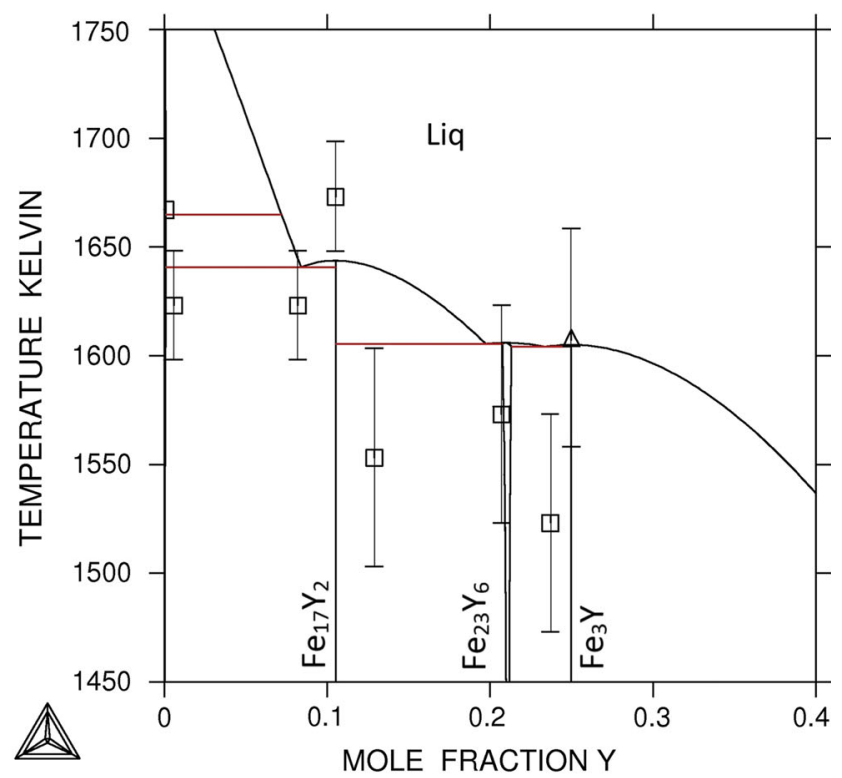

experimental data of Subramanian and Smith ${ }^{[35]}$ and calculations of Kardellass et al. ${ }^{[9]}$ in the Fig. 5 .

Based on the experimental results of heat capacity measurement performed by Mandal et al., ${ }^{[58]}$ the standard entropy at $298.15 \mathrm{~K}$ of the $\mathrm{Fe}_{17} \mathrm{Y}_{2}$ compound have been calculated equal to $34.5 \mathrm{~J} \mathrm{~K}^{-1} \mathrm{~mol}^{-1}$ in the present work. As mentioned above, the technique of the sample preparation used in the work of Mandal et al. ${ }^{[58]}$ does not allow high accuracy calculation of the standard entropy. However, the agreement between the value calculated based on $\mathrm{C}_{\mathrm{p}}$ data of Mandal et al. ${ }^{[58]}$ and value derived in the present optimization is quite acceptable (compare value of $34.5 \mathrm{~J}$ $\mathrm{K}^{-1} \mathrm{~mol}^{-1}$ based on data of Mandal et al. ${ }^{[58]}$ with $32.4 \mathrm{~J} \mathrm{~K}^{-1} \mathrm{~mol}^{-1}$ calculated using present thermodynamic description).

All available experimental and theoretical results including information that was not considered earlier ${ }^{[10,11]}$ were taken into account during the optimization of present thermodynamic description. The " $\chi^{2}$ "-criterion (see Eq 8) was calculated for the present optimization and for available in the literature thermodynamic descriptions. ${ }^{[9]}$ Evaluated results of the work of Kardellass et al. ${ }^{[9]}$ were the following: $\chi^{2}=2131.0$ for PTD $\left(\chi_{\text {inv. }}^{2}=2.4\right.$ considering only experimental data on invariant reactions, the number of independent optimized parameters $p=25$ ) and $\chi^{2}=986.3$ for ETD $\left(\chi_{\text {inv. }}^{2}=2.9, p=27\right)$. Calculated result of current optimization was $\chi^{2}=497.0\left(\chi_{\text {inv. }}^{2}=1.0\right.$, $p=18$ ). Calculation of the " $\chi^{2}$ "-criterion for each 
Table 4 Invariant reactions in the Fe-Y system: comparison between experimental data, ${ }^{[14,17,31,69]}$ calculation of Kardellass et al. ${ }^{\left[{ }^{[]}\right.}$and current results

\begin{tabular}{|c|c|c|c|c|c|c|}
\hline \multirow{2}{*}{$\frac{\text { Reaction }}{\mathrm{Liq}+\delta \mathrm{Fe} \leftrightarrow \gamma \mathrm{Fe}}$} & \multirow{2}{*}{$\frac{\text { Type }}{\text { Metatectic }}$} & \multirow{2}{*}{$\frac{\text { Temperature, } \mathrm{K}}{1665}$} & \multicolumn{3}{|c|}{ Phase composition (Y, at.\%) } & \multirow{2}{*}{$\begin{array}{r}\text { Source } \\
\text { Ref } 17,69\end{array}$} \\
\hline & & & $\ldots$ & $\ldots$ & $\cdots$ & \\
\hline & & 1665 & 7.19 & $\cdots$ & $\cdots$ & This work \\
\hline & & 1663 & 4.79 & $\ldots$ & $\ldots$ & $\mathrm{PTD}^{[9]}$ \\
\hline & & 1664 & 4.79 & $\ldots$ & $\ldots$ & $\mathrm{ETD}^{[9]}$ \\
\hline \multirow[t]{4}{*}{$\gamma \mathrm{Fe} \leftrightarrow \alpha \mathrm{Fe}+\mathrm{Fe}_{17} \mathrm{Y}_{2}$} & Peritectoid & 1184 & $\ldots$ & 0.038 & 10.50 & Ref $17,31,69$ \\
\hline & & 1185 & $\cdots$ & 0.001 & 10.50 & This work \\
\hline & & 1185 & $\ldots$ & $\ldots$ & 10.50 & $\mathrm{PTD}^{[9]}$ \\
\hline & & 1185 & $\ldots$ & $\ldots$ & 10.50 & $\mathrm{ETD}^{[9]}$ \\
\hline $\mathrm{Liq} \leftrightarrow \delta \mathrm{Fe}+\mathrm{Fe}_{17} \mathrm{Y}_{2}$ & Eutectic & 1663 & 7.19 & $\ldots$ & 10.50 & $\mathrm{ETD}^{[9]}$ \\
\hline \multirow[t]{3}{*}{$\mathrm{Liq} \leftrightarrow \gamma \mathrm{Fe}+\mathrm{Fe}_{17} \mathrm{Y}_{2}$} & Eutectic & $1623 \pm 25$ & 8.20 & $<0.60$ & 10.50 & Ref 14,17 \\
\hline & & 1641 & 8.41 & 0.10 & 10.50 & This work \\
\hline & & 1633 & 5.63 & $\ldots$ & 10.50 & $\operatorname{PTD}^{[9]}$ \\
\hline \multirow[t]{4}{*}{$\mathrm{Liq} \leftrightarrow \mathrm{Fe}_{17} \mathrm{Y}_{2}$} & Congruent & $1673 \pm 25$ & 10.50 & 10.50 & $\ldots$ & Ref 14,17 \\
\hline & & 1644 & 10.50 & 10.50 & $\ldots$ & This work \\
\hline & & 1676 & 10.50 & 10.50 & $\ldots$ & $\mathrm{PTD}^{[9]}$ \\
\hline & & 1672 & 10.50 & 10.50 & $\ldots$ & $\mathrm{ETD}^{[9]}$ \\
\hline \multirow[t]{4}{*}{$\mathrm{Liq} \leftrightarrow \mathrm{Fe}_{17} \mathrm{Y}_{2}+\mathrm{Fe}_{23} \mathrm{Y}_{6}$} & Eutectic & $\sim 1553$ & 12.90 & 10.50 & $\ldots$ & Ref 14,17 \\
\hline & & 1605 & 19.74 & 10.50 & 20.70 & This work \\
\hline & & 1605 & 18.15 & 10.50 & $\ldots$ & $\mathrm{PTD}^{[9]}$ \\
\hline & & 1638 & 17.90 & 10.50 & $\ldots$ & $\mathrm{ETD}^{[9]}$ \\
\hline \multirow[t]{4}{*}{$\mathrm{Liq} \leftrightarrow \mathrm{Fe}_{23} \mathrm{Y}_{6}$} & Congruent & $\sim 1573$ & $\ldots$ & $\ldots$ & $\ldots$ & Ref 14,17 \\
\hline & & 1606 & 20.05 & 20.05 & $\ldots$ & This work \\
\hline & & 1606 & 20.75 & 20.75 & $\ldots$ & $\mathrm{PTD}^{[9]}$ \\
\hline & & 1641 & 20.75 & 20.75 & $\ldots$ & ETD $^{[9]}$ \\
\hline \multirow[t]{4}{*}{$\mathrm{Liq} \leftrightarrow \mathrm{Fe}_{23} \mathrm{Y}_{6}+\mathrm{Fe}_{3} \mathrm{Y}$} & Eutectic & $\sim 1523$ & 23.70 & $\ldots$ & 25 & Ref 14,17 \\
\hline & & 1604 & 23.36 & 20.50 & 25 & This work \\
\hline & & 1605 & 20.70 & $\ldots$ & 25 & $\mathrm{PTD}^{[9]}$ \\
\hline & & 1640 & 21.63 & $\ldots$ & 25 & ETD $^{[9]}$ \\
\hline \multirow[t]{4}{*}{$\mathrm{Liq} \leftrightarrow \mathrm{Fe}_{3} \mathrm{Y}$} & Congruent & $\sim 1608$ & 25 & 25 & $\ldots$ & Ref 14,17 \\
\hline & & 1605 & 25 & 25 & $\ldots$ & This work \\
\hline & & 1623 & 25 & 25 & $\ldots$ & $\mathrm{PTD}^{[9]}$ \\
\hline & & 1647 & 25 & 25 & $\ldots$ & ETD $^{[9]}$ \\
\hline \multirow[t]{4}{*}{$\mathrm{Liq}+\mathrm{Fe}_{3} \mathrm{Y} \leftrightarrow \mathrm{Fe}_{2} \mathrm{Y}$} & Peritectic & $1398 \pm 25$ & $\sim 42$ & 25 & 33.30 & Ref 14,17 \\
\hline & & 1396 & 52.48 & 25 & 33.54 & This work \\
\hline & & 1409 & 44.27 & 25 & 33.30 & $\mathrm{PTD}^{[9]}$ \\
\hline & & 1397 & 48.18 & 25 & 33.30 & $\mathrm{ETD}^{[9]}$ \\
\hline \multirow[t]{4}{*}{$\mathrm{Liq} \leftrightarrow \mathrm{Fe}_{2} \mathrm{Y}+\alpha \mathrm{Y}$} & Eutectic & $1173 \pm 10$ & $\sim 66$ & $\sim 33.3$ & $>98.40$ & Ref 14,17 \\
\hline & & 1201 & 66.09 & 33.7 & 99.20 & This work \\
\hline & & 1146 & 61.18 & $\ldots$ & $\ldots$ & $\mathrm{PTD}^{[9]}$ \\
\hline & & 1118 & 63.65 & $\ldots$ & $\ldots$ & ETD $^{[9]}$ \\
\hline \multirow[t]{4}{*}{$\mathrm{Liq}+\beta \mathrm{Y} \leftrightarrow \alpha \mathrm{Y}$} & Peritectic & 1758 & $\ldots$ & $\ldots$ & $\ldots$ & Ref 69 \\
\hline & & 1756 & 98.26 & 99.74 & 99.73 & This work \\
\hline & & 1750 & 97.89 & $\ldots$ & $\ldots$ & $\mathrm{PTD}^{[9]}$ \\
\hline & & 1749 & 97.60 & $\ldots$ & $\ldots$ & $\mathrm{ETD}^{[9]}$ \\
\hline
\end{tabular}

thermodynamic description considered an identical number of experimental values of reliable literature data $(85$ experimental values including 16 points of phase equilibria). Errors of experimental values were taken according to their accuracy. It can be concluded, that thermodynamic description derived in the present work 
Fig. 3 Comparison of integral mixing enthalpies of liquid phase obtained in the present work (solid green line) and in the work of Kardellass et al. ${ }^{[9]}$ using polynomial temperature dependence of interaction parameters description (PTD, dash-dot red line) and exponential temperature dependence of Kaptay ${ }^{[66]}$ (EDT, dashed blue line) together with experimental results of Ryss et al. ${ }^{[32]}$
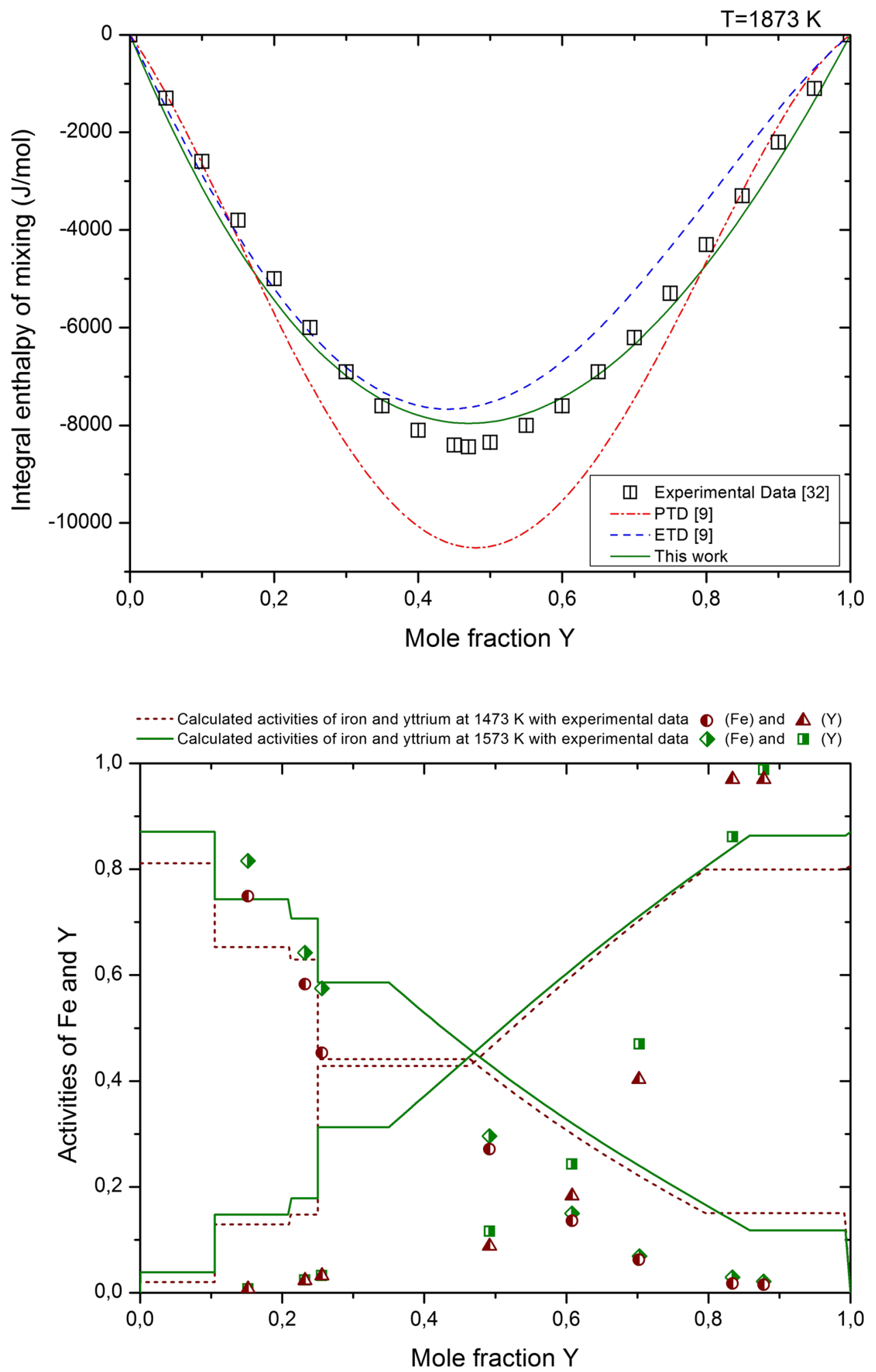

Fig. 4 Comparison of our calculated data and the experimental results of activities from the work of Nagai et al. ${ }^{[34]}$ phase do not lead to miscibility gap in the liquid phase in the whole range of temperatures of SGTE functions of pure elements. Therefore, obtained thermodynamic description is acceptable for the modeling of the highorder systems. 
Table 5 Comparison of the experimental and calculated data on Gibbs energy, enthalpy and entropy of formation of intermetallic compounds of the Fe-Y system

\begin{tabular}{|c|c|c|c|c|c|c|}
\hline $\begin{array}{l}\text { Intermetallic } \\
\text { compounds }\end{array}$ & $\begin{array}{c}\text { Temperature, } \\
\mathrm{K}\end{array}$ & $\begin{array}{l}\text { Enthalpy of formation, } \\
\qquad \mathrm{kJ}(\mathrm{mol} \mathrm{at})^{-1}\end{array}$ & $\begin{array}{l}\text { Entropy of formation, } \\
\mathrm{kJ}^{-1}(\mathrm{~mol} \mathrm{at})^{-1}\end{array}$ & $\begin{array}{l}\text { Gibbs energy of formation, } \\
\mathrm{kJ}(\mathrm{mol} \mathrm{at})^{-1}\end{array}$ & $\begin{array}{l}\text { Used } \\
\text { method }\end{array}$ & References \\
\hline \multirow[t]{13}{*}{$\mathrm{Fe}_{17} \mathrm{Y}_{2}$} & 0 & $-1.78^{*}$ & & & Ab initio & Ref 10 \\
\hline & 298.15 & -8.7 & & & Prediction (a) & Ref 11 \\
\hline & & -4.36 & & & Optimization & This work \\
\hline & & -5.99 & & & Optimization & $\mathrm{PTD}^{[9]}$ \\
\hline & & -5.29 & & & Optimization & $\mathrm{ETD}^{[9]}$ \\
\hline & 895 & $-7.93 \pm 0.01$ & $-1.72 \pm 0.02$ & $-4.6 \pm 0.6$ & EMF & Ref 11 \\
\hline & & -6.66 & -1.74 & -6.72 & Optimization & This work \\
\hline & & -8.35 & 2.838 & -10.89 & Optimization & $\mathrm{PTD}^{[9]}$ \\
\hline & & -7.66 & 1.015 & -8.57 & Optimization & $\mathrm{ETD}^{[9]}$ \\
\hline & 973 & $-6.38 \pm 0.31$ & $-1.90 \pm 0.28$ & $-4.54 \pm 0.05$ & EMF & Ref 35 \\
\hline & & -7.77 & -1.121 & -6.68 & Optimization & This work \\
\hline & & -9.47 & 1.660 & -11.09 & Optimization & $\mathrm{PTD}^{[9]}$ \\
\hline & & -8.76 & -0.167 & -8.60 & Optimization & $\mathrm{ETD}^{[9]}$ \\
\hline \multirow[t]{8}{*}{$\mathrm{Fe}_{23} \mathrm{Y}_{6}$} & 0 & $-4.85^{*}$ & & & $\mathrm{Ab}$ initio & Ref 10 \\
\hline & 298.15 & -6.25 & & & Optimization & This work \\
\hline & & -12.05 & & & Optimization & $\mathrm{PTD}^{[9]}$ \\
\hline & & -12.97 & & & Optimization & ETD $^{[9]}$ \\
\hline & 973 & $-8.09 \pm 0.49$ & $-2.24 \pm 0.44$ & $-5.91 \pm 0.07$ & EMF & Ref 35 \\
\hline & & -9.22 & -0.933 & -8.31 & Optimization & This work \\
\hline & & -11.69 & 2.970 & -14.58 & Optimization & $\mathrm{PTD}^{[9]}$ \\
\hline & & -12.65 & -0.079 & -12.57 & Optimization & $\mathrm{ETD}^{[9]}$ \\
\hline \multirow[t]{9}{*}{$\mathrm{Fe}_{3} \mathrm{Y}$} & 0 & -7.60 & & & $\mathrm{Ab}$ initio & Ref 10 \\
\hline & 298.15 & -1 & & & Prediction (a) & Ref 39 \\
\hline & & -6.96 & & & Optimization & This work \\
\hline & & -13.04 & & & Optimization & $\mathrm{PTD}^{[9]}$ \\
\hline & & -13.31 & & & Optimization & $\mathrm{ETD}^{[9]}$ \\
\hline & 973 & $-8.97 \pm 0.54$ & $-3.03 \pm 0.48$ & $-6.02 \pm 0.08$ & EMF & Ref 35 \\
\hline & & -8.94 & -0.184 & -8.76 & Optimization & This work \\
\hline & & -12.49 & 3.570 & -15.96 & Optimization & $\mathrm{PTD}^{[9]}$ \\
\hline & & -12.77 & 0.859 & -13.61 & Optimization & $\operatorname{ETD}^{[9]}$ \\
\hline \multirow[t]{9}{*}{$\mathrm{Fe}_{2} \mathrm{Y}$} & 0 & -7.87 & & & $\mathrm{Ab}$ initio & Ref 10 \\
\hline & 298.15 & -1 & & & Prediction (a) & Ref 39 \\
\hline & & -6.3 & & & Optimization & This work \\
\hline & & -9.99 & & & Optimization & $\mathrm{PTD}^{[9]}$ \\
\hline & & -12.47 & & & Optimization & $\mathrm{ETD}^{[9]}$ \\
\hline & 973 & $-7.09 \pm 0.61$ & $-0.96 \pm 0.55$ & $-6.15 \pm 0.09$ & EMF & Ref 35 \\
\hline & & -7.77 & 0.32 & -8.09 & Optimization & This work \\
\hline & & -12.55 & 2.87 & -15.34 & Optimization & $\mathrm{PTD}^{[9]}$ \\
\hline & & -11.80 & 1.14 & -12.91 & Optimization & $\mathrm{ETD}^{[9]}$ \\
\hline \multirow[t]{7}{*}{$\mathrm{FeY}$} & 0 & -5.9 & & & Interpolation & Ref 10 \\
\hline & 298.15 & -2 & & & Prediction (a) & Ref 39 \\
\hline & & -12.5 & & & Prediction (b) & Ref 37 \\
\hline & 973 & -5.3 & & -4.6 & Interpolation & Ref 35 \\
\hline & & -5.8 & & -6.0 & Interpolation & This work \\
\hline & & -9.4 & & -11.5 & Interpolation & $\mathrm{PTD}^{[9]}$ \\
\hline & & -8.8 & & -9.7 & Interpolation & $\mathrm{ETD}^{[9]}$ \\
\hline
\end{tabular}

(a)Using the Miedema theory

(b)Using Friedel-type d-band model

* These compounds are unstable at $0 K$ according to the ab initio calculation performed in the work ${ }^{[10]}$ 
Fig. 5 (a) Comparison of the formation enthalpy of intermetallic compounds obtained in the present work (green circles) and in the work of Kardellass et al. ${ }^{[9]}$ using polynomial temperature dependence of interaction parameters description (PTD, red diamonds) and exponential temperature dependence of Kaptay $^{[66]}$ (EDT, blue triangles) with experimental data of Subramanian and Smith ${ }^{[35]}$ (black squares) and (b) Comparison of the Gibbs formation energies of intermetallic compounds calculated in the present work (green circles) and in the work of Kardellass et al. ${ }^{[9]}$ using polynomial temperature dependence of interaction parameters description (PTD, red diamonds) and exponential temperature dependence of Kaptay $^{[66]}$ (EDT, blue triangles) with experimental data of Subramanian and Smith ${ }^{[35]}$ (black squares)

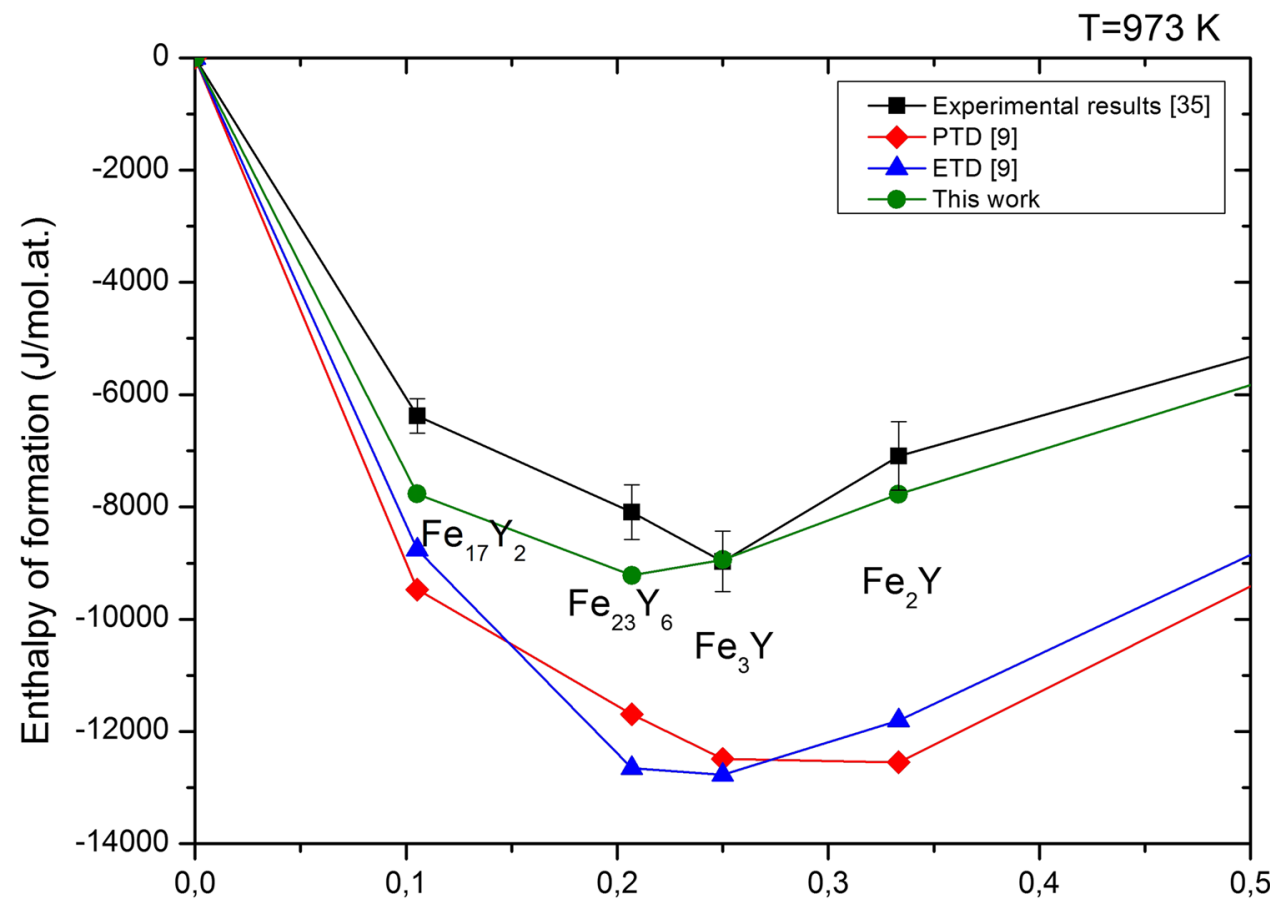

(a)
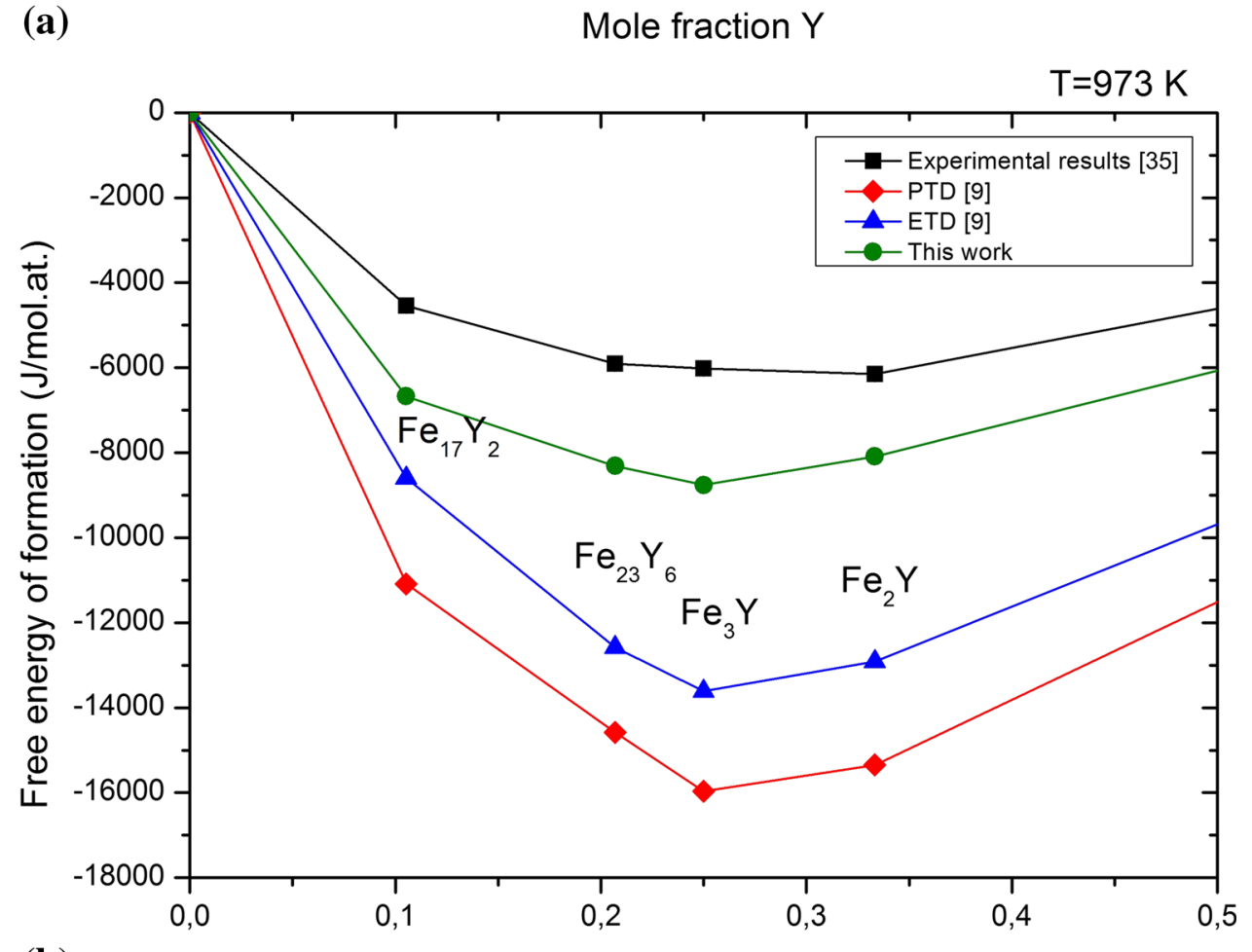

(b) 


\section{Conclusions}

Critical evaluation and optimization of all available experimental data for the $\mathrm{Fe}-\mathrm{Y}$ system have been performed in order to derive a consistent set of the Gibbs energies for all the phases in the system. Available data for intermetallic compounds, namely the experimental Gibbs energy of formation ${ }^{[11]}$ and ab-initio calculations of enthalpy of formation ${ }^{[10]}$ have been taken into account. Liquid and solid solution phases such as bcc, fcc, and hcp have been described using substitutional model. Compound energy formalism ${ }^{[71]}$ has been applied in order to describe intermetallic compounds with homogeneity range. The magnetic properties of solid phases have been taken into account. Problems of thermodynamic modelling in this system have been discussed, namely choosing, application and possible artifacts of the excess Gibbs energy descriptions. The general " $\chi$ ")-criterion (Eq 8) has been used as a method of comparison of thermodynamic descriptions considering general number of optimized parameters. In the results, it has been established that the set of thermodynamic parameters derived in the present work describes experimental data better than thermodynamic descriptions published earlier. The calculated diagram of the $\mathrm{Fe}-\mathrm{Y}$ system reproduce experimental data on phase equilibria within uncertainty. Current calculation have acceptable agreement with experimental data on the Gibbs energy, enthalpy and entropy of formation of intermetallic compound, ${ }^{[10,11,35]}$ which are in good accordance with each other. Experimental data on activities ${ }^{[34]}$ are inconsistent with the present thermodynamic description. However, values of Gibbs energy of formation calculated by Nagai et al. ${ }^{[34]}$ using obtained data on activities are in significant inconsistence with other experimental data. ${ }^{[10,11,35]}$ Considering this well accordance of the works, ${ }^{[10,11,35]}$ experimental data obtained in these works have been accepted as more reliable. New activity measurements for liquid phase in this system could help to clarify the inconsistence between data and improve thermodynamic description of the Fe-Y system.

Acknowledgments The research was supported by grants Chemistry and Materials Science Branch of the Presidium of Russian Academy of Sciences, project of Program Basic Researchs III.5.2. on 2016. Additionally, authors thank Oleksandra Krivtsova for critical reading.

\section{References}

1. V. Paul-Boncour, S. Filipek, A. Percheron-Guégan, I. Marchuk, and J. Pielaszek, Structural and Magnetic Properties of RFe2H5 Hydrides (R = Y, Er), J. Alloys Compd., 2001, 317-318, p 83-87

2. T. Leblond, V. Paul-Boncour, and A. Percheron-Guégan, Isotope Effect on the Thermodynamic and Structural Properties of Y1-
yRyFe2(H, D)x $(\gamma)$ Compounds $\quad(\mathrm{R}=\mathrm{Tb}, \quad \mathrm{Er}, \quad \mathrm{Lu} ; \quad 4.0$ $\leq \mathrm{x}(\gamma) \leq 4.5)$, J. Alloys Compd., 2007, 446-447, p 419-422

3. A. Udovsky and O. Fabrichnaya, About Oxide Dispersion Particles Chemical Compatibility with Areas Coherent Dissipation/ Sub-grains of bec-Alloys in Fe-(Cr, V, Mo, W) Systems, J. Min. Metall. B Metall., 2016, 52(2), p 185-188

4. Z. Du, W. Zhang, and Y. Zhuang, Thermodynamic Assessment of the Fe-Y System, Rare Met., 1997, 16, p 52-58

5. W.-P. Gong, T.-F. Chen, D.-J. Li, and Y. Liu, Thermodynamic Investigation of Fe-Ti-Y Ternary System, Trans. Nonferrous Met. Soc. China, 2009, 19(1), p 199-204

6. B.W. Zhang, G. Liu, and K. Han, The Fe-Y (Iron-Yttrium) System, JPE, 1992, 13(3), p 304-308

7. D. Lü, C. Guo, C. Li, and Z. Du, Thermodynamic Description of Fe-Y and Fe-Ni-Y Systems, Phys. Proc., 2013, 50, p 383-387

8. S. Kardellass, C. Servant, N. Selhaoui, A. Iddaoudi, M. Ait Amari, L. Bouirden, N. David, J.-N. Jaubert, and R. Privat, Thermodynamic Assessments of the Fe-Y and Ni-Sc Systems, MATEC Web Conf., 2013, 3, p 1008

9. S. Kardellass, C. Servant, N. Selhaoui, A. Iddaoudi, M.A. Amar, and L. Bouirden, A Thermodynamic Assessment of the IronYttrium System, J. Alloys Compd., 2014, 583, p 598-606

10. M. Mihalkovič and M. Widom, Ab Initio Calculations of Cohesive Energies of Fe-Based Glass-Forming Alloys, Phys. Rev. B, 2004, 70(14), p 144107

11. D. Gozzi, M. Iervolino, and A. Latini, Thermodynamics of FeRich Intermetallics Along the Rare Earth Series, J. Chem. Eng. Data, 2007, 52(6), p 2350-2358

12. B. Konar, J. Kim, and I.-H. Jung, Critical Systematic Evaluation and Thermodynamic Optimization of the Fe-RE System: $\mathrm{RE}=\mathrm{Gd}, \mathrm{Tb}, \mathrm{Dy}, \mathrm{Ho}, \mathrm{Er}, \mathrm{Tm}, \mathrm{Lu}$, and Y, J. Phase Equilib. Diffus., 2017, 31(12), p 1007

13. B. Konar, Critical Evaluation and Thermodynamic Optimization of the Iron-Rare-Earth Systems, McGILL University, Montreal, 2012

14. R.D. Domagala, J.J. Rausch, and D.W. Levinson, Y-Fe, Y-Ni and Y-Cu Systems, Trans. ASM, 1961, 53, p 139-155

15. M.S. Farkas and A.A. Bauer, The Solid Solubility and Constitution of Yttrium in Iron-20 to $40 \mathrm{w} / \mathrm{o}$ Chromuim Alloys, USAEC Rep. BMI, 1959, 1386, p 1-20

16. K.A. Gscheidner, Rare Earth Alloys, Van Nostrand, Princeton, NJ, 1961

17. O. Kubuschewski, Iron-Binary Phase Diagrams: Iron-Yttrium, Springer, New York, 1982

18. T.B. Massalski, Binary Alloy Phase Diagrams, Metals Park, Ohio, 1991

19. K. Taylor and C.A. Poldy, Stability of the $\mathrm{CaCu}_{5}$ Phase in Compounds Formed Between Yttrium and the 3d-Elements, $J$. Less Common Met., 1972, 27(2), p 255-257

20. M. Tenhover, B.M. Clemens, and P. Duwez, A Body Centred Cubic Phase of Elemental Yttrium Prepared by the Rapid Solidification of Yttrium-Iron Alloys, J. Phys. F: Met. Phys., 1982, 12(10), p L167-L171

21. P.I. Kripyakevich, D.P. Frankevich, and YuV Voroshilov, Compounds with $\mathrm{Th}_{6} \mathrm{Mn}_{23}$-Type Structures in Alloys of the RareEarth Metals with Manganese and Iron, Poroshkovaya Metall., 1965,5 , p $55-61$

22. K. Buschow, The Crystal Structures of the Rare-Earth Compounds of the form $\mathrm{R}_{2} \mathrm{Ni}_{17}, \mathrm{R}_{2} \mathrm{Co}_{17}$ and $\mathrm{R}_{2} \mathrm{Fe}_{17}$, J. Less Common Met., 1966, 11(3), p 204-208

23. O.I. Kharchenko, O.I. Bodak, and E.I. Gladyshevskii, Interaction of Yttrium with Metals of the Iron Family, Izv. Akad. Nauk SSSR Met., 1977, 1, p 200-205

24. H.K. Smith, J.J. Rhyne, K.A. Hardman-Rhyne, and W.E. Wallace, Thermodynamic Studies of Hydrides of $\mathrm{R}_{6} \mathrm{Fe}_{23}(\mathrm{R} \equiv \mathrm{Y}, \mathrm{Er}$, 
Ho, Lu) and $\mathrm{R}_{6} \mathrm{Mn}_{23}(\mathrm{R} \equiv \mathrm{Gd}$, Dy, Er, Ho), J. Less Common Met., 1987, 130, p 421-429

25. J. van Vucht, Note on the Structures of $\mathrm{GdFe}_{3}, \mathrm{GdNi}_{3}, \mathrm{GdCo}_{3}$ and the Corresponding Yttrium Compounds, J. Less Common Met., 1966, 10(2), p 146-147

26. K.H.J. Buschow, Intermetallic Compounds of Rare-Earth and 3d Transition Metals, Rep. Prog. Phys., 1977, 40(10), p 1179-1256

27. B.J. Beaudry, J.F. Haefling, and A.H. Daane, Some Laves Phases of Yttrium with Transition Elements, Acta Cryst., 1960, 13(9), p 743-744

28. A.E. Dwight, Factors Controlling the Occurrence of Laves Phases and $\mathrm{AB}_{5}$ Compounds Among Transition Elements, Trans. Am. Soc. Met., 1961, 53, p 479-500

29. A. Hellawell, Solid State Transitions in Manganese and Iron Solid Solutions, J. Less Common Met., 1959, 1(2), p 110-112

30. K. Buschow, Crystal Structure and Magnetic Properties of $\mathrm{YFe}_{2 \mathrm{x}} \mathrm{Al}_{2-2 \mathrm{x}}$ Compounds, J. Less Common Met., 1975, 40(3), p 361-363

31. L. Li and Z. Xhing, Solubilities of $\mathrm{Ce}, \mathrm{Nd}$ and $\mathrm{Y}$ in $\alpha-\mathrm{Fe}$, Acta Metall. Sin., 1993, 29(3), p 40-45

32. G.M. Ryss, A.I. Stroganov, YuO Esin, and P.V. Geld, Enthalpy of Formation of Liquid Fe-Y Alloy, Zh. Fiz. Khi., 1976, 50, p 771772

33. V.S. Sudavtsova, V.P. Kurach, and G.I. Batalin, Thermochemical Properties of Molten Binary Fe-(Y, Zr, Nb, Mo) Alloys, Rus. Metall. Met., 1987, 3, p 59-60

34. T. Nagai, W.-H. Han, and M. Maeda, Thermodynamic Measurement of La-Fe and Y-Fe Alloys by Multi-Knudsen Cell Mass Spectrometry, J. Alloys Compd., 2010, 507(1), p 72-76

35. P.R. Subramanian and J.F. Smith, Thermodynamics of Formation of Y-Fe Alloys, Calphad, 1984, 8(4), p 295-305

36. L.H. Bennett and R.E. Watson, A Database for Enthalpies of Formation of Binary Transition Metal Alloys, Calphad, 1981, 5(1), p 19-23

37. R.E. Watson and L.H. Bennett, Optimized Predictions for Heats of Formation of Transition-Metal Alloys II, Calphad, 1984, 8(4), p 307-321

38. A.R. Miedema, On the Heat of Formation of Solid Alloys. II, $J$. Less Common Met., 1976, 46(1), p 67-83

39. A.K. Niessen, F.R. de Boer, R. Boom, P.F. de Châtel, W. Mattens, and A.R. Miedema, Model Predictions for the Enthalpy of Formation of Transition Metal Alloys II, Calphad, 1983, 7(1), p 51-70

40. H.R. Kirchmayr, Magnetic Properties of the Compound Series $\mathrm{Y}\left(\mathrm{Mn}_{\mathrm{x}} \mathrm{Fe}_{1-\mathrm{x}}\right)_{2}$ and $\mathrm{Y}_{6}\left(\mathrm{Mn}_{\mathrm{x}} \mathrm{Fe}_{1-\mathrm{x}}\right)_{23}$, J. Appl. Phys., 1968, 39(2), p 1088-1089

41. H.R. Kirchmayr and W. Steiner, Magnetic Order of the Compound Series $\operatorname{Re}_{6}\left(\mathrm{Mn}_{\mathrm{x}} \mathrm{Fe}_{1-\mathrm{x}}\right)_{23}(\mathrm{Re}=\mathrm{Y}, \mathrm{Gd})$, J. Phys. Colloq., 1971, 32(C1), p C1-665-C1-667

42. M.J. Besnus, J.M. Bouton, and R. Clad, Crystal Structure and Magnetic Properties of $\mathrm{Y}_{6}\left(\mathrm{Fe}_{1-\mathrm{x}} \mathrm{Al}_{\mathrm{x}}\right)_{23}$ Compounds, Phys. Stat. Sol. (a), 1979, 53(1), p 351-354

43. L.X. Liao, X. Chen, Z. Altounian, and D.H. Ryan, Structure and Magnetic Properties of $\mathrm{R}_{2} \mathrm{Fe}_{17} \mathrm{C}_{\mathrm{x}}(\mathrm{x} \sim 2.5)$, Appl. Phys. Lett., 1992, 60(1), p 129-131

44. H. Fujii, M. Akayama, K. Nakao, and K. Tatami, Effect of Interstitial Hydrogen and Nitrogen on Magnetic and Structural Properties of $\mathrm{R}_{2} \mathrm{~T}_{17}(\mathrm{R} \equiv \mathrm{Y}, \mathrm{Ce}$ and $\mathrm{Sm} ; \mathrm{T} \equiv \mathrm{Fe}, \mathrm{Co}$ and $\mathrm{Ni}), J$. Alloys Compd., 1995, 219(1-2), p 10-15

45. I. Tereshina, S. Nikitin, V. Verbetsky, and A. Salamova, Transformations of Magnetic Phase Diagram as a Result of Insertion of Hydrogen and Nitrogen Atoms in the Crystalline Lattice of $\mathrm{R}_{2} \mathrm{Fe}_{17}$ Compounds, J. Alloys Compd., 2002, 336(1-2), p 36-40

46. X.C. Kou, F.R. de Boer, R. Grössinger, G. Wiesinger, H. Suzuki, H. Kitazawa, T. Takamasu, and G. Kido, Magnetic Anisotropy and Magnetic Phase Transitions in $\mathrm{R}_{2} \mathrm{Fe}_{17}$ with $\mathrm{R}=\mathrm{Y}$, Ce, $\mathrm{Pr}$,
Nd, Sm, Gd, Tb, Dy, Ho, Er, Tm and Lu, J. Magn. Magn. Mater., 1998, 177-181, p 1002-1007

47. Y.-G. Wang, F. Yang, C. Chen, N. Tang, H. Pan, and Q. Wang, Structure and Magnetic Properties of $\mathrm{Y}_{2} \mathrm{Fe}_{17-\mathrm{x}} \mathrm{Mn}_{\mathrm{x}}$ Compounds (x = 0-6), J. Alloys Compd., 1996, 242(1-2), p 66-69

48. B.-G. Shen, B. Liang, Z.-H. Cheng, H.-Y. Gong, W.-S. Zhan, H. Tang, F.R. de Boer, and K. Buschow, Magnetic Properties of $\mathrm{R}_{2} \mathrm{Fe}_{14} \mathrm{M}_{3}$ Compounds with $\mathrm{M}=\mathrm{Ga}$ and SI; $\mathrm{R}=\mathrm{Y}, \mathrm{Nd}, \mathrm{Sm}, \mathrm{Gd}$, Tb, Dy, Ho, Er and Tm, Solid State Commun., 1997, 103(2), p 7175

49. Y. Knyazev, A.G. Kuchin, and Y. Kuz'min, Optical Conductivity and Magnetic Parameters of the Intermetallic Compounds $\mathrm{R}_{2-}$ $\mathrm{Fe}_{17-\mathrm{x}} \mathrm{M}_{\mathrm{x}}(\mathrm{R}=\mathrm{Y}, \mathrm{Ce}, \mathrm{Lu} ; \mathrm{M}=\mathrm{Al}, \mathrm{Si})$, J. Alloys Compd., 2001, 327(1-2), p 34-38

50. A. Paoluzi, F. Albertini, and L. Pareti, Comparison Among the Second-Order Anisotropy Constants of RE (Pr, Nd, Sm) and $\mathrm{Fe}$ Sublattices in the $\mathrm{RE}_{2} \mathrm{Fe}_{17}$ Rhombohedral Structure. Effects of Ti substitution for Fe, J. Magn. Magn. Mater., 2000, 212(1-2), p $183-188$

51. B.-G. Shen, H.-Y. Gong, B. Liang, Z.-H. Cheng, and J.-X. Zhang, Effects of Si Substitution on the Magnetic Properties of $\mathrm{R}_{2} \mathrm{Fe}_{17}$ Compounds with $\mathrm{R} \equiv \mathrm{Y}$ and $\mathrm{Tm}, J$. Alloys Compd., 1995, 229(2), p 257-261

52. A.G. Kuchin, N.I. Kourov, Y.V. Knyazev, N.M. Kleinerman, V.V. Serikov, G.V. Ivanova, and A.S. Ermolenko, Electronic, Magnetic, and Structural Properties of the Alloys $\mathrm{Y}_{2}\left(\mathrm{Fe}_{1-\mathrm{x}} \mathrm{M}_{\mathrm{x}}\right)_{17}$, where $\mathrm{M}=\mathrm{Al}$ and Si, Phys. Stat. Sol. (a), 1996, 155(2), p 479483

53. W. Steiner, A. Planck, and G. Weihs, Crystallographic and Magnetic Properties of R.E.2(Fe, Ni)17 Alloys, J. Less Common Met., 1976, 45(1), p 143-153

54. R. Pfranger, D. Płusa, S. Szymura, and B. Wysłocki, Magnetic Properties of $\mathrm{Dy}_{2-\mathrm{x}} \mathrm{Y}_{\mathrm{x}} \mathrm{Fe}_{17}$ Compounds, Phys. $B+C, 1982$, 114(2), p 212-216

55. J. Inoue and M. Shimizu, Electronic Structure and Magnetic Properties of Y-Co, Y-Fe and Y-Mn Intermetallic Compounds, $J$. Phys. F: Met. Phys., 1985, 15(7), p 1511-1524

56. D. Givord, F. Givord, and R. Lemaire, Magnetic Properties of Iron Compounds with Yttrium, Lutetium and Gadolinium, $J$. Phys. Colloq., 1971, 32(C1), C1-668-C1-669

57. K. Koyama and H. Fujii, Nitrogen Gas-Solid Reaction Process and Basic Magnetism of the Interstitially Modified Rare-Earth 3d Transition-Metal Nitrides R2Fe17N3(R = Y, Ce, Nd, Sm) and Y2Co17N3, Phys. Rev. B, 2000, 61(14), p 9475-9493

58. K. Mandal, A. Yan, P. Kerschl, A. Handstein, O. Gutfleisch, and K.-H. Müller, The Study of Magnetocaloric Effect in $\mathrm{R}_{2} \mathrm{Fe}_{17}$ (R = Y, Pr) Alloys, J. Phys. D Appl. Phys., 2004, 37(19), p 26282631

59. J.F. Herbst and J.J. Croat, Magnetization of $\mathrm{R}_{6} \mathrm{Fe}_{23}$ Intermetallic Compounds: Molecular Field Theory Analysis, J. Appl. Phys., 1984, 55(8), p 3023-3027

60. C.A. Bechman, K. Narasimhan, W.E. Wallace, R.S. Craig, and R.A. Butera, Electronic Specific Heat and High Field Magnetization Studies on the $\mathrm{Y}_{6}\left(\mathrm{Fe}_{1-\mathrm{x}} \mathrm{Mn}_{\mathrm{x}}\right)_{23}$ System, J. Phys. Chem. Solids, 1976, 37(2), p 245-249

61. J.F. Herbst and J.J. Croat, Magnetization of $\mathrm{RFe}_{3}$ Intermetallic Compounds: Molecular Field Theory Analysis, J. Appl. Phys., 1982, 53(6), p 4304-4308

62. J. Arout Chelvane and G. Markandeyulu, Magnetic Properties of $\mathrm{Y}_{1-\mathrm{x}} \mathrm{Gd}_{\mathrm{x}} \mathrm{Fe}_{2} \mathrm{~B}_{\mathrm{y}}[\mathrm{x}=0,0.25,0.5,0.75,1 ; \mathrm{y}=0,0.1,0.15,0.2]$, J. Alloys Compd., 2006, 421(1-2), p 35-41

63. M. Brouha and K. Buschow, Pressure Dependence of the Curie Temperature of Intermetallic Compounds of Iron and Rare-Earth Elements, Th, and Zr, J. Appl. Phys., 1973, 44(4), p 1813-1816

64. Y. Muraoka, M. Shiga, and Y. Nakamura, Magnetic Properties and Mössbauer Effect of $\mathrm{A}\left(\mathrm{Fe}_{1-\mathrm{x}} \mathrm{B}_{\mathrm{x}}\right)_{2}(\mathrm{~A}=\mathrm{Y}$ or $\mathrm{Zr}, \mathrm{B}=\mathrm{Al}$ or 
Ni) Laves Phase Intermetallic Compounds, Phys. Stat. Sol. (a), 1977, 42(1), p 369-374

65. K.H.J. Buschow and R.P. van Stapele, Magnetic Properties of Some Cubic Rare-Earth-Iron Compounds of the Type $\mathrm{RFe}_{2}$ and $\mathrm{RxY}_{1-\mathrm{x}} \mathrm{Fe}_{2}$, J. Appl. Phys., 1970, 41(10), p 4066-4069

66. G. Kaptay, A New Equation for the Temperature Dependence of the Excess Gibbs Energy of Solution phases, Calphad, 2004, 28(2), p 115-124

67. SGTE Pure Element Database (UNARY): 5.0, Scientific Group Thermodata Europe, 2009

68. M. Hillert and M. Jarl, A Model for Alloying in Ferromagnetic Metals, Calphad, 1978, 2(3), p 227-238

69. A.T. Dinsdale, SGTE Data for Pure Elements, Calphad, 1991, 15(4), p 317-425

70. O. Redlich and A.T. Kister, Algebraic Representation of Thermodynamic Properties and the Classification of Solutions, Ind. Eng. Chem., 1948, 40(2), p 345-348

71. M. Hillert, The Compound Energy Formalism, J. Alloys Compd., 2001, 320(2), p 161-176

72. H.L. Lukas, S.G. Fries, and B. Sundman, Computational Thermodynamics The Calphad Method, Cambridge University Press, New York, 2007
73. J.-O. Andersson, T. Helander, L. Höglund, P. Shi, and B. Sundman, Thermo-Calc \& DICTRA, Computational Tools for Materials Science, Calphad, 2002, 26(2), p 273-312

74. R. Schmid-Fetzer, D. Andersson, P.Y. Chevalier, L. Eleno, O. Fabrichnaya, U.R. Kattner, B. Sundman, C. Wang, A. Watson, L. Zabdyr, and M. Zinkevich, Assessment Techniques, Database Design and Software Facilities for Thermodynamics and Diffusion, Calphad, 2007, 31(1), p 38-52

75. G. Kaptay, The Exponential Excess Gibbs Energy Model Revisited, Calphad, 2017, 56, p 169-184

76. A.L. Udovskii, Computer Modelling of Phase Diagrams, Thermodynamic Properties, and Structure of Multicomponent Systems, Izv. Akad. Nauk SSSR Met., 1990, 2, p 136-157

77. B. Konar, J. Kim, and I.-H. Jung, Critical Systematic Evaluation and Thermodynamic Optimization of the Fe-RE System: $\mathrm{RE}=\mathrm{La}, \mathrm{Ce}, \mathrm{Pr}, \mathrm{Nd}$ and Sm, J. Phase Equilib. Diffus., 2016, 37(4), p 438-458 